Revista lus et Praxis, Año 17, No 1, 2011, pp. 139 - 176

ISSN 0717 - 2877

Universidad de Talca - Facultad de Ciencias Jurídicas y Sociales

"La quiebra sin bienes.

Una aproximación desde el análisis económico del Derecho"

Raúl Núñez Ojeda - Nicolás Carrasco Delgado

\title{
LA QUIEBRA SIN BIENES. UNA APROXIMACIÓN DESDE EL ANÁLISIS ECONÓMICO DEL DERECHO*
}

\author{
BANKRUPTCY WITH NO ASSETS. \\ AN APPROXIMATION FROM THE ECONOMIC ANALYSIS OF LAW
}

Raúl Núñez Ojeda ${ }^{* *}$
Nicolás Carrasco Delgado ${ }^{* * *}$

RESUMEN

El presente trabajo trata de la quiebra sin bienes, esto es, de aquellos juicios en donde hay inexistencia o insuficiencia del patrimonio del fallido para afrontar los costos que supone la quiebra. En ambos supuestos, no se justifica económicamente dicho proceso. Sin embargo, nuestra legislación no contempla mecanismos apropiados para impedir el inicio o continuación de un juicio de quiebras en donde se acredite la inexistencia o insuficiencias de activos, los que se promueven, a pesar de sus altos costos, con la única finalidad de satisfacer la venganza de los acreedores, incentivados, estos últimos, por la posibilidad de perseguir criminalmente al deudor.

ABSTRACT

The present paper is about the bankruptcy with no assets, that is, those trials where there is lack or insufficiency of the assets of bankrupt to face the costs of bankruptcy has involved. In both cases, no such process is economically justified. However, our legislation does not provide appropriate mechanisms to prevent the beginning

or continuation of a bankruptcies trial in which it is established the absence or insufficiency of assets, which are promoted despite their high costs, with the only purpose of satisfying the revenge of creditors, motivated the latest by the possibility of prosecuting the debtor criminally.

\footnotetext{
* Este trabajo se enmarca dentro del proyecto FONDECYT regular N 1100530, titulado "Hacia una nueva justicia concursal", cuyo investigador principal es el profesor Dr. Raúl NúÑez OJEDA, de la Pontificia Universidad Católica de Valparaíso. Trabajo recibido el 20 de diciembre de 2010 y aprobado el 27 de enero de 2011.

${ }^{* *}$ Licenciado en Ciencias Jurídicas por la Universidad de Valparaíso (Chile); Doctor en Derecho por la Universidad Pompeu Fabra de Barcelona (España); Profesor Asociado de Derecho Procesal en la Pontificia Universidad Católica de Valparaíso (Chile). Correo electrónico: raul.nunez@ucv.cl.

*** Licenciado en Ciencias Jurídicas y Candidato a Magíster en Derecho por la Universidad de Chile; Ayudante de Derecho Procesal en la Facultad de Derecho de la misma Universidad. Correo electrónico: ncarrascod@gmail.com.
} 
PALABRAS CLAVE

Derecho Comercial, Análisis Económico del Derecho, Derecho de Quiebras, Derecho

Procesal Civil

KEY WORDS

Commercial Law, Economic Analysis of Law, Bankruptcy, Civil Procedural Law

\section{INTRODUCCIÓN}

La Quiebra sin bienes la podemos definir como aquel procedimiento concursal de quiebras en donde el fallido no posee bienes (inexistencia de masa activa), o bien, poseyéndolos son completamente insuficientes para satisfacer los costos asociados al proceso de quiebra (insuficiencia de masa activa) ${ }^{1}$.

El problema vinculado a la quiebra sin bienes, se refiere entonces, a un déficit de la masa activa de la quiebra (obtenida vía incautación²), a los efectos de afrontar los costos que involucra un procedimiento de quiebra.

La inexistencia de masa activa, se traduce en que el fallido no posee patrimonio alguno, de forma que todo esfuerzo por llevar a cabo el proceso de quiebra, significará un desgaste del sistema sin recuperación futura de créditos. En este supuesto, incluso las cien unidades de fomento necesarias para solicitar la quiebra ${ }^{3}$ (cuando es pedida por un tercero ajeno al fallido) serán un costo no recuperable.

Por su parte, la insuficiencia de masa activa, se plantea frente a un escenario en donde, el fallido posee bienes, pero dicho activo resulta precario a los efectos de solventar los costos asociados al proceso de quiebras, ya no sólo referente a la consignación previa que debe realizar el acreedor solicitante, sino que también, referente a la recuperación de las costas judiciales involucradas en el mencionado proceso de quiebras. No se trata, en consecuencia, sólo de una masa activa incapaz de satisfacer las exigencias de pago a acreedores preferentes y/o valistas, sino que, peor aún, se trata de una masa activa imposibilitada

\footnotetext{
${ }^{1}$ Es importante hacer presente que una conceptualización como la indicada es posible de ser encontrada en el artículo $2^{\circ}$ transitorio de la Ley de Quiebras, que dispone: "Sin perjuicio de lo establecido en el artículo precedente, en todas aquellas quiebras que carezcan de bienes o en que éstos no alcancen a cubrir los gastos necesarios para su prosecución, el respectivo tribunal, de oficio o a petición de parte, dentro del plazo de sesenta días corridos desde la vigencia de esta ley, deberá decretar el sobreseimiento temporal. La resolución se notificará mediante la publicación de un aviso en el periódico señalado para la publicación de la declaración de quiebra, si hubiere bienes; y en la forma prescrita en el artículo 50 del Código de Procedimiento Civil, si careciere de ellos".

${ }^{2}$ Artículos 94 a 100 de la Ley de Quiebras (Título VII).

${ }^{3}$ Artículo 44 inciso 2 de la Ley de Quiebras dispone: "Junto con solicitar la quiebra, el acreedor peticionario deberá acompañar vale vista o boleta bancaria a la orden del tribunal por una suma equivalente a cien unidades de fomento, para subvenir a los gastos iniciales de la quiebra. Dicha suma será considerada como un crédito del solicitante en contra del fallido, que gozará de la preferencia establecida en el número 4 del artículo 2472 del Código Civil”.
} 
de soportar el pago de aquellas sumas que el proceso de quiebra involucra, en toda su estructura.

En ambos supuestos, la tasa de recuperación de créditos es igual a cero, generándose, asimismo, pérdidas por el inicio y prosecución del juicio, ya que los costos que éste involucra se perderán irremediablemente, siendo soportados, única y exclusivamente, por el acreedor y por el sistema público de adjudicación.

Expuestas las ideas anteriores, podríamos decir que la existencia de quiebras sin bienes, no resultaría posible frente a acreedores racionales ${ }^{4}$, ya que éstos, no tendrían incentivos para promover una declaratoria de quiebra, toda vez que, ejercitando su acción concursal, terminarían en un peor escenario que si no lo hicieran.

Asimismo, podríamos suponer que el legislador de quiebras, considerando dichos supuestos, ha establecido mecanismos idóneos para no posibilitar un esfuerzo del sistema público de adjudicación, que a la postre, resultará inútil.

Ni lo uno ni lo otro, ya que, siguen existiendo quiebras sin bienes ${ }^{5}$, y además, nuestra legislación (y en esto, no es la única) no dispone de mecanismos tendientes a evitar que un proceso de quiebras se lleve a efecto, sabiendo que sus resultados serán infructuosos en lo que se refiere a la recuperación de créditos.

Ahora bien, debemos aclarar que el momento temporal en que nos situamos al analizar la quiebra sin bienes, se refiere al momento de la rendición, por parte del síndico, de su cuenta definitiva, esto es, una vez concluido el proceso de realización de la masa activa, o de la declaración de inexistencia de bienes, luego de terminada la incautación. Lo anterior, porque resulta evidente que, situarnos al momento de la declaratoria de quiebras, para calificar la inexistencia o insuficiencia de masa activa, concluiría en un examen poco clarificador de la situación patrimonial del fallido, toda vez que el juicio de quiebras puede extender, en su tramitación, sus efectos antes de la declaratoria de quiebras, por medio de acciones paulianas especiales o bien, de reintegro de bienes del fallido ${ }^{6}$. En efecto, algunas quiebras con inexistencia o insuficiencia inicial de masa activa, pierden dicha calidad con el ejercicio de acciones de reintegro. Por lo mismo, el objeto de este trabajo se refiere a aquellas quiebras que continúan siendo de aquellas que hemos denominado como sin bienes, una vez

\footnotetext{
${ }^{4}$ Para una visión de la racionalidad en el Derecho confrontar por todos: Habermas, Jürgen, Faktizität und Geltung, Suhrkamp, Frankfurt, 1992, pp. 109 y ss.

${ }^{5}$ En razón de incentivos que distorsionan indebidamente la búsqueda de eficiencia del sistema y que tienden a promover la venganza privada del acreedor por medio de la incoación de procesos penales.

${ }^{6}$ Un problema asociado al ejercicio de dichas acciones (y que, excede los términos de este trabajo), se refiere a la ineficiente regulación de dichas clases de acciones, lo que trasunta en imposibilitar un resultado satisfactorio en la recuperación de créditos.
} 
que las posibilidades procesales de ejercicio de dichas acciones han resultado infructuosas, o bien, simplemente no fueron ejercidas.

Por último, nuestra legislación contiene, respecto de lo que hemos venido desarrollando, dos deficiencias: (a) No dispone de regulaciones tendientes a coartar la posibilidad de ejercitar procesos concursales de quiebras, en casos en donde razonablemente existirán supuestos de inexistencia o insuficiencia de masa activa, y peor aún, tampoco contempla salidas eficientes a quiebras en dichas condiciones, que tiendan a detener la pérdida de recursos una vez que ya no es posible pensar en una recuperación de las acreencias verificadas; y (b) Contempla incentivos, quizás no deseados, pero reales, para que el proceso de quiebra sea una excusa para una persecución penal del deudor que no posee bienes, o que los posee en forma insuficiente, generando espacios para la venganza privada en escenarios en donde no siempre se encuentra envuelto un interés social prevalente ${ }^{7}$.

\section{ANÁlisis ECONÓMICO DEL DERECHO DE LA QUIEBRA SIN BIENES}

El Análisis Económico del Derecho tiene por objeto aplicar instrumentos de la ciencia económica moderna en el ámbito jurídico.

En el presente acápite, efectuaremos un estudio acerca de los fundamentos de la legislación de quiebras y de su correlación con los propósitos buscados por el Análisis Económico del Derecho, pretendiendo entregar un sustento de justificación sobre el cual construir la propuesta, que en este texto, se realiza respecto de las quiebras sin bienes.

\section{Eficiencia como fundamento de la legislación de quiebras}

Desde la óptica del Análisis Económico del Derecho, las instituciones jurídicas de derecho privado (dentro de las que se encuentran, el Derecho de Quiebras), deberían tender hacia la búsqueda y consecución de la eficiencia.

Sin embargo, el problema que afronta el Análisis Económico del Derecho en el logro de dicho objetivo, es la dificultad de introducir el concepto de eficiencia para la evaluación, aplicación y modificación del sistema legal. En este sentido, los operadores del Derecho (jueces, abogados, etc.) resultan reacios a aceptar que conceptos económicos puedan ayudar para entender, mejorar y justificar ciertas normas o decisiones jurisdiccionales. Lo anterior resulta clara-

\footnotetext{
${ }^{7}$ Más allá de ello, la tendencia actual precisamente se enmarca en despenalizar conductas relacionadas con la quiebra o de la insuficiencia económica, pues sólo constituirá un atentado a un bien jurídico tutelable, cuando estemos frente a un ataque a un bien macro-social, en este caso, el crédito dentro del sistema económico, cometido por sujetos con una posición de poder capaz de transgredir dicho bien. Sandoval López, Ricardo, Derecho comercial. La insolvencia de la empresa, (tomo IV), Editorial Jurídica de Chile, Santiago, 2007, p. 219.
} 
mente evidenciable en países como el nuestro, en donde la tradición jurídica del Civil Law, encuentra en la literalidad de la ley el motivo de su estudio, no reconociendo en ella, sustratos económicos que pudieran orientar su interpretación o aplicación.

No obstante lo anterior, incluso dentro de las opiniones críticas a la aceptación del Análisis Económico del Derecho en sistemas como el nuestro ${ }^{8}$, existe cierto grado de acuerdo en el sentido de que existen regulaciones legales especiales que incluyen, por su propia naturaleza, expresiones que van más allá de lo estrictamente legal, permitiendo que pueda replicarse a su respecto consideraciones provenientes de otras áreas, como lo pueden ser, las económicas.

Una de dichas áreas se refiere al Derecho de Quiebras, en cuya evolución, la liquidación del activo del deudor-fallido, como una forma de retribuciónsanción, ha dejado paso hacia la continuación de la empresa en insolvencia, en aquellos casos, en donde la permanencia de la actividad económica se justifica en razón de ciertas variables económicas, como es el caso de las empresas en crisis viables.

Dicho tránsito, se ha venido dando por nuestra legislación de quiebras, sobre todo desde la dictación, a comienzos de la década del ochenta, de la Ley $N^{\circ}$ 18.175. Dicha normativa ha sido objeto de diversas modificaciones, sin embargo, en los últimos años ha existido un impulso reformador, con el objetivo de reforzar el sistema privado de administración de quiebras, por medio de la dictación de la Ley $\mathrm{N}^{\circ} 20.004$, que establece normas sobre fortalecimiento de la transparencia en la administración de la quiebra, fortalecimiento de la labor de los síndicos y de la Superintendencia de Quiebras.

Asimismo, se dictó la Ley $N^{\circ} 20.073$, que modifica la Ley $N^{\circ} 18.175$ en lo relativo a los convenios concursales. Esta ley, publicada en el Diario Oficial el 20 de noviembre de 2005, simplemente transformó toda la normativa anterior sobre convenios en una regulación moderna, desjudicializada e innovadora. Esta ley se hace cargo de los avances que al respecto habían operado en el

\footnotetext{
${ }^{8}$ Ver: SPECTOR, Horacio. "Justicia y Bienestar desde una perspectiva de derecho comparado", en KLUGER, Viviana (Comp.), Análisis Económico del Derecho, Heliasta, Buenos Aires, 2006, pp. 57-58; y Cossıo Díaz, José Ramón, Derecho y Análisis Económico, Fondo de Cultura Económica, Ciudad de México, México, 1997, pp. 270-272.

${ }^{9}$ Esta ley publicada en el Diario Oficial el 8 de marzo de 2005, no establece un cambio general en el sistema de Quiebras, sino que reafirma el sistema privatista existente, introduciéndole modificaciones en todos aquellos aspectos que habían demostrado ser deficitarios en la práctica durante más de veinte años desde la entrada en vigencia de la Ley $\mathrm{N}^{\circ} 18.175$. En muchos aspectos, la mencionada ley no hace más que incorporar criterios jurisprudenciales que ya se habían afianzado en nuestros tribunales, en cambio en otros, se introdujeron reformas que implican nuevos tratamientos normativos, como por ejemplo, en lo que respecta al sistema de designación de síndicos privados, y en lo relacionado con las nuevas facultades sancionatorias, normativas y participativas como sujeto procesal y auxiliar de la administración de justicia de la Superintendencia de Quiebras.
} 
derecho comparado. Se mejora y diversifica lo relativo a los convenios judiciales preventivos, introduciendo nuevos órganos de convenios como el experto facilitador, se aclaran las normas sobre convenios simplemente judiciales, se introducen mecanismos que posibiliten el salvataje de empresas en dificultad económica, a través de exámenes previos, y se privatiza el desarrollo de los convenios de aquellas sociedades que se encuentran bajo la fiscalización de la Superintendencia de Valores y Seguros a través de la tramitación de los mismos ante un tribunal arbitral ${ }^{10}$.

Lo importante de resaltar en dichas reformas lo constituye el hecho de que ellas fueron impulsadas por el Poder Ejecutivo, y se enmarcaron en el contexto de la agenda pro crecimiento, de la cual nace la necesidad, en esta materia, de facilitar los acuerdos entre los acreedores y el deudor en casos en que nos encontremos frente a una empresa con problemas económicos, de manera de permitir procedimientos preventivos de salvamento de empresas en crisis. Este sistema es considerado más beneficioso para la comunidad y para el proceso productivo que el hecho de llegar a una situación de liquidación forzosa que, por los tiempos que implica, lleva a una desvalorización de los activos de la empresa, afectando las fuentes laborales de los trabajadores y cortando la cadena de pagos.

La necesidad de modernizar la ley de quiebras surge de la constatación de que la modernización económica de Chile debe provenir de normativas que faciliten y promuevan la eficiencia económica y el buen desempeño del mercado. Entonces se hace imperiosa la adecuación de la ley de quiebras a dichos principios, de manera que se permita una reorganización de las empresas en crisis en casos que sean viables financieramente, o en caso contrario, favorecer una liquidación rápida de los activos, permitir la disponibilidad de créditos, la disminución de los costos de transacción que impiden el desenvolvimiento económico, acrecentar los espacios de transparencia y reducir los incentivos jurídicos y económicos para entrar a un procedimiento de quiebra. Por último, uno de los problemas más importantes para el desarrollo productivo de los países en vías emergentes o en vías de desarrollo, es la escasa disponibilidad de crédito. Por lo mismo, se debe establecer un sistema normativo que facilite una alta tasa de recuperación de los créditos en caso de incumplimiento de las obligaciones. Con ello, el riesgo asociado al préstamo se hace menor, y consecuencialmente, las posibilidades de otorgar créditos en mejores condiciones aumentan. Para lo anterior, los factores de tiempo de duración de los procesos concursales, transparencia, profesionalización de los agentes que en los mismos

\footnotetext{
${ }^{10}$ Sobre la reforma de la Ley $N^{\circ} 20.073$, ver por todos: SANDOval, Derecho comercial, cit. nota n. 7 , pp. 58 y ss.
} 
procesos intervienen y el establecimiento de una normativa legal moderna son fundamentales.

Para poder cumplir dichos propósitos, se constituyó una comisión técnica por los señores Claudio Bonilla, Rafael MerY, José Tagle, Ronald Fischer y Rolf Lüders ${ }^{11}$, quienes identifican, en un estudio elaborado al efecto, seis problemas de la normativa chilena sobre quiebras. En lo que aquí interesa, la primera y más importante de las dificultades encontradas, se refiere a que: “(...) la legislación nacional no contempla explícitamente el objetivo de mantener en funcionamiento la empresa en problemas cuando aparezca viable, para lo cual proponen explicitar el objetivo de eficiencia". En dicho sentido señalan:

"A diferencia de las legislaciones más modernas de quiebras, la ley chilena no contempla explícitamente el objetivo de mantener en funcionamiento la empresa en problemas cuando ella aparezca viable. Si bien existe la intención del legislador de proteger, ante la cesación de pagos, los intereses legítimos, tanto del deudor como de sus acreedores, pareciera ser que la preocupación prioritaria es el respeto de la igualdad entre los acreedores valistas y el pleno respeto de los privilegios y preferencias establecidas en la ley. Podríamos decir que el objetivo primordial de nuestra legislación es obtener el pronto, eficiente y equitativo pago de los acreedores. El artículo $1^{\circ}$ de nuestra ley expresa como su principal objeto el: "realizar en un solo procedimiento los bienes de una persona natural o jurídica, a fin de proveer al pago de sus deudas, en los casos y en la forma determinada por la ley". Si bien es cierto, la introducción de algunas modificaciones mediante la Ley 18.598 del año 1987, y en particular la inclusión del artículo 177 bis, están dirigidas a facilitar la obtención de un convenio entre acreedores y deudor, ello no pareciera ser la manifestación de un principio general que gobierne a toda nuestra legislación concursal"12.

"Creemos que es necesario hacer explícito un nuevo objetivo de la ley de quiebras. Este debería ser: Proveer el pago de las deudas de la manera más eficiente posible, decidiendo entre la conservación de la empresa viable y la liquidación eficiente y equitativa de la empresa no viable". Con un objetivo así declarado se conjugan los conceptos de "rehabilitación del deudor", presente en leyes como la americana, francesa o peruana, y el concepto de "pago equitativo a los acreedores", presente en leyes como la chilena. El nuevo objetivo debiera ser el principio general que rija el contenido de la ley" "(...) Una empresa es viable (conviene mantener su giro) si tiene utilidades operacionales no negativas y el valor presente de éstas es no inferior al valor de liquidación de la empresa"13.

Gran parte de las observaciones y recomendaciones efectuadas en dicho estudio, y específicamente, la propuesta de eficiencia que las inspira, fueron incorporadas en las leyes antes indicadas, constituyendo la búsqueda de la

\footnotetext{
${ }^{11}$ Bonilla, Claudio; FISCher, Ronald; LÜDERS, Rolf; MeRY, Rafael; TAGLE, José, Análisis y Recomendaciones para una reforma de la ley de quiebras, Documentos de Trabajo del Centro de Economía Aplicada del Departamento de Ingeniería Industrial de la Universidad de Chile, 2004, N 191, pp. 6-17.

12 Bonilla; Fischer; Lüders; Merr; Tagle, Análisis, cit. nota n. 11, p. 6.

${ }^{13}$ Bonilla; Fischer; Lüders; MerY; TAgle, Análisis, cit. nota n. 11, pp. 6-7.
} 
eficiencia un principio explícito que fundamenta dicha normativa, a cuya luz deben ser interpretadas y aplicadas sus normas.

En consecuencia, en la actual legislación de quiebras encontramos un terreno fértil para que el Análisis Económico del Derecho pueda servir de ayuda para entender y mejorar la regulación existente, más aún, si el sustrato en que descansa dicha normativa encuentra su correlato con el fin que pretende alcanzar la Economía del Derecho.

\section{Objetivos de Análisis Económico del Derecho en el proceso de quiebras}

Hemos concluido el acápite anterior, señalando que la eficiencia constituye un principio que subyace en la legislación nacional de quiebras. De esta manera, es posible que el Análisis Económico del Derecho pueda aportar sus instrumentos de mejor manera, toda vez que los principios que orientan ambas ramas son similares.

Con todo, es necesario establecer algunas ideas acerca del concepto de eficiencia (desarrollado, a continuación, en el acápite b.i) y de qué manera dicho criterio, se involucra en las particularidades del proceso de quiebra (desarrollado, a continuación, en el acápite b.ii)

\section{i. La eficiencia}

Las distintas concepciones del Análisis Económico del Derecho utilizan el concepto de eficiencia ${ }^{14}$, existiendo diversas manifestaciones del mismo, lo que hace difícil su estudio. Así, existe una eficiencia en el intercambio, expresada en la idea de conmutatividad y de beneficio económico recíproco de los agentes. Por otro lado, es posible hablar de una eficiencia en la producción, cuando dada cierta combinación de factores productivos es posible obtener una mayor generación de bienes y/o servicios, considerando al efecto, la Frontera de Posibilidades de Producción y la Ley de los Rendimientos Marginales Físicos Decrecientes. Por último, es posible entender la eficiencia desde la perspectiva del consumidor, como combinación de productos, en aquellos casos en donde existiendo modificación de los componentes de productos ofrecidos a los destinatarios finales, se logra mayor utilidad para algunos de éstos, sin perjudicar a los restantes.

Sin perjuicio de lo anterior y a fin de evitar problemas conceptuales, los teóricos del Análisis Económico del Derecho, en concordancia con los avances de la ciencia económica, han tratado de desarrollar un concepto único de eficiencia. Al respecto, podemos identificar los siguientes:

\footnotetext{
${ }^{14}$ Para un estudio crítico acerca de la eficiencia, ver, entre otros: Coleman, Jules, "The Grounds of
} Welfare", The Yale Law Journal Vol. 112, pp. 1511-1543 
a. Óptimo de Pareto: Se define, como sigue: Es aquella situación social en la que sólo se consigue una mejora para alguien, si al menos otra persona sufre por tal motivo un perjuicio ${ }^{15}$. Dicho óptimo, conlleva una eficiencia en la asignación de los recursos, para lo que se requiere el cumplimiento de tres exigencias: (a) Producción Eficiente: Que pretende la búsqueda de una productividad marginal en cada factor de producción, que es aquel incremento que resulta de aplicar a la producción del bien de que se trata una unidad adicional del factor respectivo, produciendo un incremento en la producción total del bien; (b) Consumo Eficiente: Que se traduce en lograr aquel estado en donde no es posible alcanzar o conseguir más acuerdos de intercambio en beneficio mutuo, de manera que las relaciones de utilidad marginal de los bienes (aquella proporción adicional de utilidad que se genera para una persona ante una mayor disponibilidad del bien) son iguales para todos los ciudadanos, y (c) Estructura Productiva Eficiente. Que supone que los costos que suponga la mayor producción de un bien $(\mathrm{X})$, a costa de la menor producción de otro $(\mathrm{Y})$, coincidan exactamente con la cantidad del bien Y que los ciudadanos estén dispuestos a renunciar, para disfrutar de una mayor producción de X.

b. Criterio Kaldor-HICKS ${ }^{16}$ : Este criterio fue expuesto por Hicks en 1939, con el objetivo de lograr un criterio superior a Pareto, frente a las múltiples deficiencias que significaba asumir dicho criterio, tales como, la constatación de que en la generalidad de los contextos es posible encontrar múltiples óptimos de paretianos; constituye un instrumento que se aplica de manera estática; además, tendría sentido, solamente, dentro en un marco limitado de posibilidades en las que se muevan los agentes involucrados, ya que, cuando mayor es el horizonte del tiempo y otros elementos involucrados en el bienestar de los agentes, mayor es la disconformidad de las conclusiones de Pareto con la realidad; conjuntamente, una determinada combinación productiva, sólo es definible cuando se conoce la dotación inicial de recursos de los miembros de una sociedad; por último, y en relación con el Derecho, el óptimo de Pareto no se adecuaría a la dinámica jurídica de la solución de controversias, en donde, en la generalidad de los casos, solamente es posible beneficiar a una persona a costa de perjudicar a otra ${ }^{17}$.

\footnotetext{
${ }^{15}$ Ver: Shafer, Hans-Bernd; Ott, Claus, Manual de Análisis Económico del Derecho Civil, Tecnos, Madrid, 1991, pp. 39-45, y POSNer, Richard, El análisis económico del Derecho, Fondo de Cultura Económica, Ciudad de México, 1992, pp. 19-21.

${ }^{16}$ Shafer; Ott, Manual de Análisis, cit. nota n. 15, pp. 45-58, y Posner, El análisis, cit. nota n. 15, pp. $21-25$.

${ }^{17}$ Ver por todos: CabAnellas, Guillermo, "El Análisis Económico del Derecho. Evolución Histórica. Metas e Instrumentos", en Kluger, Análisis Económico, cit. nota n. 8, pp. 33-35.
} 
Respecto de esto último, Hicks describió una decisión superior a Pareto, como aquella en virtud de la cual un miembro de la sociedad resulta favorecido, y como mínimo, otro resulta perjudicado. Dicho estado sólo resultaría justificable desde la perspectiva del bienestar social, cuando el beneficiado se encuentra en situación de indemnizar al perjudicado (aunque, en la práctica, no lo haga), y a pesar de que así obre, de todas maneras sigue teniendo alguna ventaja.

Eficiencia como regla de la subasta para la toma de decisiones: Fue expuesta por POSNER en $1977^{18}$, y se refiere a la manera eficiente en que el derecho debería regular la forma de asignación de derechos, en el sentido de que dicho derecho debería ser subastado al mejor postor, o sea, a quien se encuentre dispuesto a pagar por él el precio más alto. De esta manera, existe una evaluación personal de cada interesado acerca de sus intereses, lo que se demostraría de acuerdo a su predisposición al pago.

Más allá de las críticas que es posible realizar a cada uno de dichos criterios de eficiencia, ellos nos sirven, indudablemente, para poder disponer de un elemento de juicio sobre el cual valorar la normativa nacional sobre quiebras.

Al respecto, si consideramos la regulación de las distintas instituciones de nuestro Derecho de Quiebras, podríamos considerar que el criterio de eficiencia como regla de la subasta para la toma de decisiones, constituye un test válido de aplicación a la normativa nacional, ya que existen algunos mecanismos legales que se basan precisamente en dicho criterio, como por ejemplo, la adjudicación de un bien en el marco de la venta por unidad económica (artículo 124 de la Ley de Quiebras) o bien, las subastas de bienes a que daría lugar la aplicación del artículo 57 inciso final de la Ley de Quiebras. Lo anterior, se ve reforzado por el hecho de que la legislación de quiebras tiene por objeto resguardar predominantemente el interés privado de los participantes, resultando determinante, la capacidad económica del agente, frente a lo cual, el criterio de eficiencia que se indica es indiferente en su valoración.

\section{ii. Reducción de costos del sistema concursal}

Según POSNeR ${ }^{19}$, las metas u objetivos del sistema procesal, desde un punto de vista económico, son minimizar la suma de dos tipos de costos. El primero

\footnotetext{
${ }^{18}$ Posner, El análisis, cit. nota n. 15, p. 11. Además, consultar: Veujanovski, Cento, Economía del Derecho. Un texto Introductorio, Ediciones Universidad Diego Portales, Santiago, 1990, pp. 39-42.

${ }^{19}$ Ver: POSNer, El análisis, cit. nota n. 15, pp. 516-517, y COOTER, Robert; ULEN, Thomas, Derecho y Economía, Fondo de Cultura Económica, Ciudad de México, 1998, pp. 476-478. También consultar sobre la litigación y el proceso legal: SHAvELL, Steven, Fundations of Economic Analysis of Law, Belknap Press of Harvard University Press, Cambridge, 2004, pp. 387 y ss.
} 
de ellos es el costo de las decisiones judiciales erróneas. Y el segundo son los costos del sistema procesal. ${ }^{20}$

Sabiendo que los recursos son escasos y las necesidades ilimitadas (dentro de las que se encuentran las necesidades de acceso a la justicia), no sería económicamente viable, que por ejemplo, se gastará ilimitadamente en el sistema procesal con el objeto de reducir a cero la tasa de errores. Es necesario convivir con la existencia de los errores en el marco del proceso, y con un sistema procesal que funcione a un nivel que no genere necesariamente la mejor prestación del servicio de justicia (que puede ser excesivamente cara, pero no justificada).

El problema de escasez (aplicado al proceso) choca con el hecho de que en todo proceso, civil o penal, se requiere el respeto a las exigencias del debido proceso. En otros términos, si queremos minimizar los costos señalados, dicha disminución de costos no puede operar a un nivel tal que desconozca los costos asociados a las garantías del debido proceso. Dichas exigencias deben salvaguardarse, por muy caras que resulten (si es el caso que no es posible la reducción de sus costos). En este sentido, al analizar la teoría económica del proceso legal, Cooter y Ulen señalan que: "Las reglas procesales imponen así ciertas restricciones a la toma de decisiones por parte del tribunal que no serían respetadas por los apostadores profesionales. Las restricciones son casi siempre más estrictas en los países del derecho común cuando los juzgados conocen de casos, que en los países del derecho civil no tienen jurados. En general, un tribunal no falla según que el demandado haya hecho lo que se asevera en la reclamación. Más bien, el tribunal decide si los hechos admitidos por las reglas de procedimiento legal apoyan la reclamación". "Las reglas del procedimiento a veces contradicen a las reglas económicas de la toma de decisiones en incertidumbre, pero existen amplias áreas de acuerdo, por ejemplo, puede argüirse que si las reglas procesales imponen restricciones a los tribunales, dentro de estas fronteras razonan los jurados y los jueces como personas que toman decisiones económicas racionales. Las reglas procesales prescriben un marco cuya justificación no es necesariamente económica, pero dentro de ese marco puede operar la lógica económica"21.

En relación con las dos clases de costos, que el derecho procesal concursal debería tender a eliminar, si es que pretende un proceso de quiebras eficiente, es en primer lugar lo referente a la reducción de los costos del error, lo que no será objeto de análisis en el presente trabajo, no obstante indicar que, la

\footnotetext{
${ }^{20}$ Para una visión del sistema procesal civil de conjunto ver por todos: MARINONI, Luiz Gilherme; PéreZ Ragone, Álvaro; Núñez OjedA, Raúl, Fundamentos del proceso civil. Hacia una teoría de la adjudicación, Abeledo Perrot, Santiago, 2010, pp. 3 y ss.

${ }^{21}$ Cooter; Ulen, Derecho y EConomía, cit. nota n. 19, p. 483.
} 
reducción de dicho costo viene dada, fundamentalmente, por la existencia de tribunales especializados en materia concursal, como ocurre en la legislación española moderna de quiebras, en donde la función jurisdiccional respecto del problema de la insolvencia es enfrentada por medio de cortes técnicas y con jueces dotados de amplias atribuciones con la finalidad de reducir los márgenes de error ${ }^{22}$.

Solamente, vamos a tratar como objetivo de eficiencia procesal la reducción de los costos del proceso de quiebras, que se encuentra constituido por una serie de reglas y prácticas procesales que originan costos terciarios o administrativos, cuya característica es que no generan, en su gasto, rentabilidad alguna, sino que sólo permiten el funcionamiento del sistema.

Una primera aproximación a este tema viene dado por el hecho de que se ha comprobado que los costos administrativos de un arreglo son menores que los costos administrativos de un juicio, de esta manera, los arreglos que igualan los resultados de los juicios reducen los costos sociales en la solución de controversias $^{23}$. Es por ello, que la reforma a la legislación de quiebras, que se indicó anteriormente, no sólo dispuso de una regulación nueva en aspectos vinculados con el proceso de quiebras, sino que también innovó fundamentalmente en lo referente a los convenios concursales, dando espacios para la negociación, sobre la base de que, precisamente, el juicio importa una alternativa más costosa que las posibilidades de acuerdo entre los sujetos interesados.

Ahora bien, avanzando en el tema, debemos señalar que cuando nos encontramos en presencia de una quiebra sin bienes, es porque se optó definiti-

\footnotetext{
${ }^{22}$ Estos juzgados están basados en la profesionalización de los jueces que forman parte de dichos Tribunales. Con todo, debe señalarse que también se contempla en la Ley Orgánica del Poder Judicial, la especialización en la segunda instancia. Así, el artículo 82.4 señala que: "También conocerán de los recursos que establezca la ley contra las resoluciones dictadas en primera instancia por los juzgados de lo mercantil, salvo las que se dicten en incidentes concursales que resuelvan cuestiones de materia laboral, debiendo especializarse a tal fin una o varias de sus Secciones, de conformidad con lo previsto en el Art. 98 de la presente Ley Orgánica. Asimismo, la Sección o Secciones de la Audiencia Provincial de Alicante que se especialicen al amparo de lo previsto en el párrafo anterior conocerán, además, en segunda instancia y en forma exclusiva, de todos aquellos recursos a los que se refiere el artículo 101 del Reglamento № 40/94 del Consejo de la Unión Europea, de 20 de diciembre de 1993, sobre la marca comunitaria y el Reglamento 6/2002, del Consejo de la Unión Europea, de 12 de diciembre de 2001, sobre los dibujos y modelos comunitarios. En el ejercicio de esta competencia extenderán su jurisdicción a todo el territorio nacional y a estos solos efectos se denominarán Tribunales de Marcas Comunitaria". Con la existencia de esta doble instancia se pretende evitar los defectos de los antiguos Tribunales de Comercio, suprimidos en el año 1868, a través del Decreto de Unificación de Fueros de 6 de diciembre de 1868, toda vez que una de las críticas hechas a los mismos se derivaba de la no profesionalización de la segunda instancia. Debe dejarse en claro que los Juzgados de lo Mercantil se configuran no como una nueva jurisdicción sino como órganos especializados de la jurisdicción civil con competencia objetiva fijada por la Ley. En el ámbito concursal los juzgados de lo Mercantil conocen de cuantas cuestiones se susciten en materia concursal, en términos previstos en su ley reguladora.
}

${ }^{23}$ Cooter; Ulen, Derecho y EConomía, cit. nota n. 19, p. 477. 
vamente por la vía procesal, lo que importa la asunción de una serie de costos para el sistema.

En efecto, la quiebra debe ser uno de los procedimientos que, por su propia naturaleza, lleva implícito una serie de gastos ineludibles. Por lo mismo y constatando dicha realidad, es que la legislación nacional exige al acreedor solicitante, una consignación a los efectos de poder efectuar la petición de declaratoria de quiebras (44 inciso 2 Ley de Quiebras). Dicha consignación alcanza las cien Unidades de Fomento, monto que es independiente de las costas no cubiertas por dicha suma y de los honorarios del abogado patrocinante. Sin embargo, adicionalmente, con la declaratoria de la quiebra, se ponen en movimiento una serie de órganos concursales, tales como, el síndico de quiebras, la junta de acreedores y la Superintendencia de Quiebras, generándose costos de tiempo y recursos a fin de permitir el funcionamiento, en el proceso, de cada uno de dichos participantes.

Respecto de esto último, la regulación legal de la participación de cada uno de dichos órganos no coadyuva a la consecución de los objetivos antes indicados, toda vez que, normalmente, los síndicos contratarán asesores a fin de llevar y ejecutar tareas complejas tales como: incautaciones, estudios contables, averiguaciones de activo, etc. Por su parte, la junta de acreedores requiere ciertos quórum para su funcionamiento ${ }^{24} \mathrm{y}$ a efectos de la adopción de acuerdos $^{25}$,

\footnotetext{
${ }^{24}$ La regla general es que las reuniones de la junta de acreedores se constituirán cuando concurran dos o más acreedores que representen un porcentaje no inferior al veinticinco por ciento de los créditos con derecho a voto, salvo indudablemente que la ley establezca un quórum especial (artículo 102 inciso $5^{\circ}$ de la Ley de Quiebras). La primera junta de acreedores se constituirá cuando concurran: (a) Dos o más acreedores; (b) Que representen en conjunto dos tercios del pasivo de la quiebra, a lo menos. Si no se reuniere el quórum anterior, se dejará constancia de ello y el tribunal practicará una segunda citación no antes de cinco días ni después de diez días hábiles, indicando el lugar, día, hora y naturaleza de la reunión, así como la indicación de que se trata de la segunda citación a la primera junta de acreedores. La notificación se efectuará por aviso y la segunda reunión se celebrará con los acreedores que asistan (artículo 106 de la Ley de Quiebras).

${ }^{25}$ La regla general es que los acuerdos se adoptarán con el voto conforme de no menos de dos acreedores que sumen mayoría absoluta de los créditos presentes en la reunión con derecho a voto, salvo que la ley exija una mayoría especial. En caso de empate, corresponderá decidir a quien presida la reunión de acuerdo a lo que luego se dirá. Debemos indicar que la norma establece un doble quórum, por una parte, debe ser adoptado el acuerdo con la concurrencia de dos o más acreedores, y por otra parte, dichos acreedores deben tener una participación no menor a la mayoría absoluta de los créditos presentes en la reunión (artículo 102 inciso $4^{\circ}$ de la Ley de Quiebras). La norma indica que la mayoría absoluta debe ser calificada respecto de los créditos presentes, o sea, los créditos concurrentes a la junta respectiva y no a los créditos aceptados para votar en la junta, toda vez que puede darse el caso que estos últimos sean más, pero que no concurran a la junta. Ejemplos de quórum distintos para la adopción de acuerdos, encontramos en: (a) Si la proposición de convenio judicial preventivo es presentada con el apoyo de dos o más acreedores que representen más del $66 \%$ del total pasivo, el juez citará a una junta de acreedores que debe resolver sobre si acepta dichas proposiciones de convenio. La junta debe celebrarse dentro del plazo de treinta días desde la notificación por aviso de la resolución del tribunal que recaiga en la proposición (artículo 177 quáter $\mathrm{N}^{\circ} 1$ de la Ley de Quiebras); (b) Podrán ser
} 
los que muchas veces no se logran, generando consecuencialmente mayores dilapidaciones de tiempo y recursos para los otros órganos de la quiebra, tal como ha sido detectado por informes técnicos sobre la materia ${ }^{26}$. Por último, la Superintendencia de Quiebras ejerce funciones de supervigilancia que se han acrecentado con la Ley $N^{\circ} 20.004$, facilitando, dicha normativa, la puesta en conocimiento de hechos de su incumbencia, no obstante que en definitiva el análisis y fiscalización resulta, de todas maneras, mediata y sobre la base de antecedentes escritos, más que de una efectiva inspección del actuar de los síndicos ${ }^{27}$.

Todos los hechos antes señalados, llevan a que el proceso de quiebras sea considerado un procedimiento caro y $\operatorname{largo}^{28}$, pronunciándose en este sentido,

sometidas a arbitraje, en conformidad a los artículos 180 a 183 de la Ley de Quiebras, las proposiciones de convenio de cualquier deudor, si éste lo acuerda con sus acreedores que representen a lo menos el $66 \%$ del total pasivo, debidamente certificado en conformidad a lo dispuesto en el inciso segundo del artículo 177 bis (artículo 184 de la Ley de Quiebras); (c) La designación del experto facilitador se hará con el voto de uno o más de los acreedores, que representen más del $50 \%$ del total del pasivo con derecho a voto; en caso contrario, se considerará fracasada la gestión. Los acreedores hipotecarios y privilegiados no perderán sus preferencias por la circunstancia de participar y votar en esta junta, y podrán impetrar las medidas conservativas que procedan. En caso de que el experto facilitador formule una proposición de convenio, ésta deberá ser votada en junta de acreedores dentro del plazo de 15 días contado desde la notificación por aviso de la proposición (artículo 177 ter incisos 1, 2, 3, 4 y 10 de la Ley de Quiebras), y (d) Adopción de acuerdo de la continuación efectiva del giro del fallido, total o parcial con la aprobación de la junta de acreedores con el acuerdo de a lo menos dos tercios del pasivo de la quiebra con derecho a voto (artículo 102 de la Ley de Quiebras).

${ }^{26}$ Bonilla; Fischer; LÜders; Merr; TAGle, Análisis, cit. nota n. 11, p. 77.

${ }^{27}$ Ver artículo $8^{\circ}$ de la Ley $N^{\circ} 18.175$.

28 "Para medir el tiempo que demora el proceso de quiebra de una empresa se contó en meses el tiempo transcurrido desde la declaración de quiebra hasta la publicación de la última resolución, encontrando un plazo promedio de 40,7 meses y una desviación estándar de 20,9 meses. Estos datos provienen de nuestra muestra de 32 empresas" (BOnilla; FisCher; LüDeRs; MerY; TAGLE, Análisis, cit. nota n. 11, p. 77) y para el Banco Mundial en el Informe sobre Observancia de Estándares y Códigos, (Chile) "(..) 15.- La ley de insolvencia establece un procedimiento de liquidación de quiebra tradicional, el cual es en la práctica bastante ineficiente. Los procedimientos de quiebra abarcan a todos los activos y obligaciones del deudor (incluso obligaciones no del pasado), excepto aquellos activos y obligaciones expresamente excluidos por ley (ejemplo: hipotecas o activos en prenda). La adjudicación de quiebra tiene certeza inmediata y efecto retroactivo. La realización de un estado de quiebra, en teoría, debiera ser prontamente completada de modo de satisfacer los requerimientos de los acreedores con las ganancias obtenidas. En la práctica, sin embargo, las liquidaciones son procesos largos. Su promedio de duración es 24 a 36 meses. Una vez las reclamaciones privilegiadas y garantizadas son pagadas, los acreedores no garantizados (acreedores valistas o sin privilegio) típicamente reciben porcentajes de distribución muy bajos. Como la ley no establece tratamiento de reclamaciones subordinadas en procedimientos de insolvencia, el efecto de la quiebra de un deudor sobre el acuerdo de subordinación de deuda es incierto" (BANCo Mundial, Informe sobre Observancia de Estándares y Códigos, Chile, junio 2004, punto: 15. En: http://www-wds.worldbank.org/external/default/main?menuPK=64187510 \&pagePK $=64193027 \&$ piPK $=64187937 \&$ theSitePK=523679\&menuPK $=64154159 \&$ searchMenuPK=6 4258544\&theSitePK=523679\&entityID=000160016_20060126181835\&searchMenuPK=64258544 \&theSitePK=523679 [visitado el 14/06/2010]. 
el Banco Mundial, y también, el informe técnico elaborado por los profesores Bonilla, Fischer, Mery, Lüders Y Tagle.

De dichos estudios se llega a la conclusión de que el promedio de duración de una quiebra puede alcanzar fácilmente los tres años de vigencia, con una tasa de recuperación media no superior al $40 \%$ y, respecto de los acreedores valistas, solamente de un $3 \%{ }^{29}$.

Obviamente que la tasa de recuperación de las denominadas quiebras sin bienes resulta cero, no obstante ello, existen inhabilidades e incompatibilidades que excluyen a un sujeto de la vida del comercio $^{30}$, inhibiéndolo para ejercer nuevas actividades que pudieran servir para el pago de los acreedores en tiempo más oportuno. La manera de poner fin a dichas inhabilidades es por medio de la rehabilitación ${ }^{31}$, que exige de parte del fallido, el pago del crédito, o bien, la absolución en sede de calificación criminal, lo que no permite un término eficiente al proceso, ya que lo primero no será habitualmente posible (precisamente estamos en presencia de una quiebra sin bienes), y lo segundo, de acuerdo a la forma en que el legislador ha tipificado los delitos concursales, resulta altamente improbable, ya que se presume de antemano la culpabilidad o el actuar fraudulento del fallido ${ }^{32}$.

De esta manera, frente a una quiebra sin bienes, resulta necesario preguntarnos si existe algún criterio de eficiencia contemplado en nuestra legislación que propenda a poner término a un despilfarro innecesario de recursos, ya sea impidiendo la declaración de quiebras en donde existe alta posibilidad de inexistencia o insuficiencia de masa activa, o bien, terminando aquellos procesos ya iniciados, en donde las posibilidades de inexistencia o insuficiencia de masa activa resulten constatables en el procedimiento.

La respuesta es negativa, porque el presupuesto normativo para la declaración de quiebras, viene dado por la cesación de pagos (artículo $43 \mathrm{~N}^{\circ} 1$ de la Ley de Quiebras) y por otras causales, que de alguna manera, son expresión o son reveladores de un estado de cesación de pagos por parte del deudor (artículo

\footnotetext{
${ }^{29}$ Bonilla; Fischer; Lüders; Mery; TAgle, Análisis, cit. nota n. 11, p. 77.

${ }^{30}$ Inhabilidades que se manifiestan en: (a) Que el síndico recibirá toda la correspondencia o cartas que pudieran ser dirigidas desde y hacia el fallido (artículo $52 \mathrm{~N}^{\circ} 4$ de la Ley de Quiebras); (b) La orden de que ninguna persona puede pagar o entregar mercaderías a su persona (artículo $52 \mathrm{~N}^{\circ} 5$ de la Ley de Quiebras); (c) El desasimiento, que significa la pérdida de la administración del fallido de todos sus bienes, de pleno derecho, por la sentencia que declara la quiebra (artículo 64 de la Ley de Quiebras); (d) La sanción de inoponibilidad de todo acto o contrato que ejecute el fallido después de dictada la sentencia que declara la quiebra (artículo 72 de la Ley de Quiebras), y (e) Una serie de inhabilidades para actuar en la vida del comercio, como por ejemplo, imposibilidad de ser director de sociedades anónimas (artículo $35 \mathrm{~N}^{\circ} 3$ de la Ley $\mathrm{N}^{\circ}$ 18.046).

${ }^{31}$ Título XIV de la Ley de Quiebras, artículos 235 a 240 de la Ley de Quiebras.

${ }^{32}$ Volveremos, sobre este punto, más adelante.
} 
$43 \mathrm{~N}^{\circ} 2$ y No 3 de la Ley de Quiebras). Dicho presupuesto legal se vincula y asimila a la noción de estado patrimonial en incapacidad de hacer frente a las obligaciones asumidas por el deudor ${ }^{33}$, aunque la mayoría de nuestra doctrina considera que al efecto, bastarían los meros incumplimientos a obligaciones con las características indicadas en el artículo $43 \mathrm{~N}^{0} 1$ de la Ley de Quiebras ${ }^{34}$.

Cualquiera sea la interpretación que se sostenga al efecto, lo importante para los fines de este trabajo, es que no constituye un requisito de procedencia de la declaración de quiebra la prueba acerca de la capacidad de la masa activa para no solventar los costes que supone un proceso de quiebras.

Sin embargo, lo anterior debería ser esperable si es que pretendemos minimizar los costos del sistema procesal concursal, considerando que cada uno de los elementos de juicio que racionalmente deberían considerarse para evaluar el desincentivo a un litigio innecesario se presentan en los supuestos de las quiebras sin bienes. En efecto, todas las disputas judiciales, ocasionan: (a) Daños propios del conflicto; (b) Costos asociados a la presentación de una reclamación, y (c) Valores esperados de la reclamación.

La política legislativa podría jugar con dichos elementos a fin de incentivar o desincentivar ciertos litigios, así por ejemplo, si quisiéramos aumentar los costos de ir a juicio podríamos establecer una tasa adicional a la presentación de la reclamación. Asimismo, si la política legislativa quisiera incentivar la presentación de ciertas acciones, podríamos aumentar el valor esperado de la reclamación por medio de sanciones pecuniarias a favor del triunfador en la disputa y regular, a su favor, el pago de las costas.

Pues bien, resulta que en los casos de quiebras sin bienes se dan, por su naturaleza, todos los elementos que llevan a que se desincentive su litigación. En efecto, un proceso de quiebras en donde se dan presupuestos de inexistencia y/o insuficiencia de masa activa genera una serie de daños en el deudor-fallido, al ser inhabilitado para actuar en la vida del comercio produciendo, consecuencialmente, mayores perjuicios a sus propios acreedores, ya que sacan de circulación a un agente que con su trabajo podría generar rentabilidades y pago a sus acreencias, incluso peor aún, considerando dicha inhabilidad futura, un deudor en situación de insolvencia previa a una quiebra, tendrá mayores incentivos para adoptar medidas fraudulentas tendientes a resguardar su posición, por el riesgo cierto de dichas inhabilidades ${ }^{35}$. Además, como se ha visto, el proceso

\footnotetext{
${ }_{33}$ Puga Vial, Juan Esteban, Derecho Concursal. El juicio de Quiebras, Tomo I, Editorial Jurídica de Chile, Santiago, 1999, p. 70.

${ }^{34}$ Goudeau Gómez, Bayardo, "Concepto sobre la insolvencia, cesación de pagos, suspensión de pagos, crisis económica y empresas en dificultad", en Román Rodríguez, Juan Pablo (Coord.), Salvamento de las empresas en crisis, Editorial Jurídica de Chile, Santiago, 2001, p. 177.

${ }^{35}$ En este sentido: Bonilla; Fischer; Lüders; Merr; Tagle, Análisis, cit. nota n. 11, p. 13.
} 
de quiebra importa costos asociados a la presentación de la reclamación que ya son de cierta manera prohibitivos para algunos acreedores, y que dada la forma en que se configura la inexistencia y/o insuficiencia de masa activa, no resulta esperable, siquiera, la recuperación de dichos costos. Por último, el valor esperado de la reclamación en los supuestos de quiebra sin bienes, es cero.

Considerando todos estos aspectos, la legislación de quiebras debería, en miras de un principio de eficiencia, generar los mecanismos procesales necesarios, a fin de que solamente aquellas pretensiones con posibilidades ciertas de recuperación de créditos puedan sobrepasar el filtro del costo de la reclamación. En otras palabras, el proceso de quiebras debe estar disponible para aquellos casos en donde las pretensiones de los acreedores generen tasas de recuperación, de manera de solventar, a lo menos, los costos del sistema, ya que de otra forma no se justifica un procedimiento que no es capaz de generar rentabilidad social, o bien, un escenario más óptimo que el primero, sin juicio de quiebras.

En efecto, aplicando cualquier concepto de eficiencia, tenemos que el proceso de quiebras debe llevar a una razonable posibilidad de recuperación de acreencias, de modo que el ejercicio de la acción respectiva posibilite a los acreedores encontrarse de alguna manera mejor, luego del juicio, que sin él. En este sentido, si era plausible evitar un juicio de quiebra sin bienes, y termina siendo, de todas maneras, una quiebra con dicho calificativo, de todas formas la opción por el proceso jurisdiccional termina siendo válida, ya que el error no puede ser evitado totalmente (resulta, en esta lógica, más caro). Lo sustancial es que, en dichos casos, la legislación plantee mecanismos sencillos de poner fin al proceso de quiebra y a todos sus efectos perniciosos, que imposibilitan el ejercicio de la actividad económica de los agentes involucrados.

La manera en que dicho objetivo puede lograrse se desarrollará posteriormente, cuando tratemos la propuesta de reformulación del sistema nacional de la quiebra sin bienes, con todo, se adelanta al respecto, la idea de que sea de cargo del acreedor el cumplimiento de una exigencia legal tendiente a probar que el deudor-fallido posee un patrimonio suficiente a los efectos de posibilitar una tasa de recuperación que permita solventar, por lo menos, el pago de los costos asociados a la quiebra. Asimismo y en esa misma lógica, debe ser de cargo del acreedor la indicación de las acciones tendientes a posibilitar el reintegro de bienes que el deudor ha distraído de su patrimonio, debiendo las mismas no encontrarse prescritas y ser fundamentadas de manera de entender su plausibilidad y efectividad.

De la forma antes señalada, la legislación estaría aumentando el costo de la presentación de una reclamación tendiente a declarar la quiebra del fallido, con la finalidad de que el proceso de quiebras solamente exista cuando las posibilidades de satisfacción de los acreedores genere alguna rentabilidad 
social, mejorando su posición y no, únicamente, provocando mayores costos para el sistema.

Vinculado con lo anterior, tenemos que el proceso de quiebras no puede constituirse en la excusa para la venganza privada, que en términos del Análisis Económico del Derecho, se refiere al abuso del proceso ${ }^{36}$. En efecto, en presencia de quiebra sin bienes, el sistema procesal, bajo el prisma de la eficiencia y consecuentemente, de la reducción de sus costes, no puede justificar reclamaciones que solamente generarán pérdidas de bienestar social al no lograr recuperación alguna de los créditos reclamados. En otras palabras, no se puede justificar reclamaciones irracionales en aquellos supuestos en donde se genera gran cantidad de costos al sistema y en donde el valor esperado probable de la reclamación sea menor al costo mismo de la reclamación. Permitir dichas conductas significaría poner en marcha la actividad jurisdiccional con la única finalidad de satisfacer los ánimos de venganza privada de los acreedores, permitiendo incrementar los daños ya ocasionados por el no pago de sus créditos por medio de la inhabilidad del deudor y de la persecución penal, sujetando lo primero a lo segundo, produciéndose una doble condena al fallido.

De hecho, el único objetivo de una reclamación de un acreedor de una quiebra sin bienes, es el lograr el castigo civil y penal de su deudor fallido, lo que puede resultar altamente peligroso si consideramos que en nuestro país, seis de cada 10 emprendimientos comerciales fracasan, y asimismo, la causal tendiente a declarar la quiebra no opera sobre la base de una insolvencia real sino que, fundamentalmente, del incumplimiento de obligaciones. Lo anterior, genera un espacio para conductas oportunistas dolosas que originan mayores niveles de estigmatización ${ }^{37}$, impidiendo la declaración de la propia quiebra, dificultando así, la reestructuración de la empresa en crisis y la prevención de un mayor perjuicio a los acreedores.

Desde un punto de vista económico, la solicitud de quiebra sin bienes puede constituir un caso paradigmático de la figura procesal de abuso del procedimiento, porque existiendo el derecho de solicitarla, los costos de su adopción son soportados fundamentalmente y por largo tiempo por quien no la solicita (el costo de la inhabilidad es mayor que el costo de la consignación exigida), existiendo el incentivo de abusar de dicho instrumento con miras a la obtención de una sanción penal.

La forma de poner término al abuso del procedimiento es desplazar los costos del cumplimiento a la parte que haga la solicitud, pues con dicho desplazamiento se elimina el incentivo para el abuso, al tener dicha parte que hacerse

${ }^{36}$ Sobre el tema, consultar por todo: Catalano, Elena Maria, L'abuso del processo, Giuffrè Editore, Milano, 2004, pp. 9 y ss.

${ }^{37}$ Bonilla; Fischer; LÜDers; MerY; TAGle, Análisis, cit. nota n. 11, p. 13. 
responsable de la plausibilidad y efectividad de la petición ${ }^{38}$, en cuanto a que la misma producirá niveles de rentabilidad y recuperación de créditos superiores a los costos terciarios involucrados.

Por último, evitar la prolongación de procesos no justificados de acuerdo con razones de eficiencia tiene una explicación económica, en cuanto a que la duración del proceso produce efectivamente mayores costos al sistema, de hecho, en el estudio de Bonilla, Fischer, Mery, Lüders y Tagle, se prueba que cuando los acreedores no muestran interés en el proceso de la quiebra (fundamentalmente, por su demora y por la escasa recuperación de sus créditos), lo que se evidencia en la baja asistencia a las juntas de acreedores, los costos de administración en que incurre el síndico de quiebras son más altos, de forma que incluso los montos consignados para la prosecución del proceso ${ }^{39}$, terminan siendo insuficientes, engrosando las imposibilidades de recuperación. Adicionalmente, la duración del proceso de quiebras genera expectativas infundadas en acreedores que no verificaron en el periodo ordinario, lo que aumenta las verificaciones extraordinarias, generando mayores costos de oportunidad de los acreedores ordinarios y mayores pérdidas para el sistema en general.

\section{LEGISLACIONES COMPARADAS SOBRE LA QUIEBRA SIN BIENES}

A continuación, describiremos la manera en que la legislación española y alemana han enfrentado el problema de la quiebra sin bienes. De lo que allí se señale, se sacarán conclusiones con la finalidad de efectuar, posteriormente en el capítulo IV.b, un análisis comparativo con la legislación nacional sobre la quiebra sin bienes.

\section{España}

La legislación española, en lo que se refiere a la quiebra sin bienes (inexistencia de bienes o derechos), dispone una legislación más armónica que la nacional, y tiene como finalidad poner pronto fin al proceso una vez que se acredite dicho presupuesto.

En efecto, de acuerdo al artículo 176 NNo $^{4}$ de la Ley № 22/2003, procederá la conclusión del concurso, en cualquier estado del procedimiento, cuando se compruebe la inexistencia de bienes y derechos del concursado, así como de terceros responsables con los que satisfacer a los acreedores. ${ }^{40}$

${ }^{38}$ CoOter; Ulen, Derecho y Economía, cit. nota n. 19, p. 503.

39 Bonilla; Fischer; Lüders; Merr; Tagle, Análisis, cit. nota n. 11, p. 79.

${ }^{40}$ Ver en extenso el comentario del artículo en: Bellido, Rafael, "Causas de conclusión del concurso", en Rojo, Ángel; Betrán, Emilio (Dirs.), Comentario a la ley Concursal, Tomo II, Civitas, Madrid, 2004, pp. 2617 y ss. 
Dicha norma resulta fundamental, a efectos de entender que la legislación española de quiebras pretende evitar la continuación y prolongación de un proceso de quiebras, en aquellos supuestos en donde no se justifica, por la inexistencia de bienes y derechos del concursado, otorgando la facultad de cerrar el concurso en cualquier estado del proceso cuando resulte evidente el hecho antes señalado.

Ahora bien, la comprobación de la inexistencia de bienes y derechos del concursado, va a emanar de un informe de la Administración Concursal ${ }^{41}$, el que razonará inexcusablemente acerca de que no existen acciones viables de reintegración de la masa activa ni de responsabilidad de terceros pendientes de ser ejercitadas. En consecuencia, existe una tramitación resumida, técnica y que no se traduce en duplicidad de procedimientos ni en pruebas externas a los órganos de la quiebra, por lo que el costo asociado a la conclusión del concurso, resulta bajo y proporcionado a la naturaleza del problema de que se trata. Del informe de la administración concursal se dará audiencia (traslado) a las demás partes por el término de quince días, luego de lo cual, el Tribunal resolverá. En caso de que exista oposición al informe de la administración concursal, dicha objeción se tramitará por medio de un incidente.

Ahora bien, para poder declarar la conclusión del concurso, en caso de inexistencia de bienes o derechos del deudor, se requiere que haya concluido la sección de calificación o estén pendientes demandas de reintegración de la masa activa o de exigencia de responsabilidad de terceros, salvo que las correspondientes acciones hubiesen sido objeto de cesión. Por lo tanto, se vincula el ámbito civil con el criminal, permitiéndose la terminación del proceso de quiebras, sólo si la causa criminal termina en la calificación fortuita de la insolvencia (artículo 176.3 de la Ley № 22/2003).

Ahora bien, la quiebra concluida por inexistencia de bienes dará lugar a los siguientes efectos (artículo 178 de la Ley No 22/2003), a saber:

1. Cesarán las limitaciones de las facultades de administración y disposición del deudor.

2. El deudor quedará responsable del pago de los créditos restantes. Los acreedores podrán iniciar ejecuciones singulares, en tanto no se acuerde la reapertura del concurso o no se declare nuevo concurso.

\footnotetext{
${ }^{41}$ Dicho órgano constituye una de las principales novedades de la Ley № 22/2003 y se erige como un estrecho colaborador del juez en la Administración del Concurso. Es un órgano colegiado y de carácter técnico, designado por el propio juez del concurso, con facultades vinculadas con el deudor, cuyo patrimonio administra e interviene, con la adopción de decisiones dentro del concurso, con los terceros, con los cuales se comunica, y en relación con las diversas competencias asignadas a los demás órganos del concurso, desplazando en protagonismo al Ministerio Fiscal y a la propia Junta de Acreedores. Ver por todos: PAcheco Vergara, Andrés, La Administración Concursal, Editorial Aranzadi, Pamplona, 2009, passim, y TIRADO, Ignacio, Los administradores concursales, Civitas, Madrid, 2005, passim.
} 
3. En los casos de conclusión del concurso por inexistencia de bienes y derechos del deudor persona jurídica, la resolución judicial que la declare acordará su extinción y dispondrá el cierre de su hoja de inscripción en los registros públicos que corresponda, a cuyo efecto se expedirá mandamiento conteniendo testimonio de la resolución firme.

Lo anterior determina que, en caso de quiebra sin bienes, la legislación española dispone de mecanismos rápidos y técnicos a fin de dar por terminado el proceso, cesando las inhabilidades propias de la declaración de quiebra, existiendo solamente una vinculación entre la conclusión del proceso de quiebra con la calificación penal, de forma que la existencia de delitos concursales especiales, impediría la terminación del proceso y el cese de las inhabilidades civiles para el fallido, mientras mantengan sus efectos las sentencias respectivas.

\section{Alemania}

La normativa alemana sobre quiebras ${ }^{42}$ refleja de mejor medida las vinculaciones jurídicas y económicas en torno a la eficiencia. Al respecto, dicha legislación, consciente de la pérdida de recursos que produce una sustanciación de un proceso de insolvencia, faculta al órgano jurisdiccional para poner término a la quiebra y a las inhabilidades pertinentes, cuando compruebe que no existen bienes suficientes para solventar los costos que involucra el proceso de quiebras. ${ }^{43}$

En Alemania, la solución dada al problema de la quiebra sin bienes, termina siendo más extrema que la legislación española, ya que en esta última normativa se requiere que el proceso de quiebras se haya iniciado y que el órgano de administración emita su informe sobre la inexistencia de bienes y derechos del deudor-fallido. En cambio, en la legislación germana, el Tribunal de la Insolvencia debe rechazar todo requerimiento de apertura del procedimiento de insolvencia cuando aparezca que el deudor carece de bienes suficientes para subvenir los costes del procedimiento (parágrafo 26.1 del Código de Insolvencia alemán).

Lo anterior, es con prescindencia del hecho de que la carencia de bienes del deudor no constituye un presupuesto para la apertura del procedimiento de insolvencia ${ }^{44}$, sin embargo, el legislador alemán, consciente de la ineficiencia que supone tramitar una quiebra, que no soportará sus costos, es que opta, en beneficio de los mismos acreedores, por cerrar la posibilidad de apertura a dicho procedimiento. De hecho, el objetivo del procedimiento de insolvencia es

${ }^{42}$ Contenida en el Código de Insolvencia alemán, y la Ley Introductoria, las que fueron publicadas en el Registro Legislativo Federal (Bundesgesetzblatt) el 5 de octubre de 1994.

${ }^{43}$ En castellano, ver el comentario al sistema concursal alemán en: DAsso, Ariel A., Derecho concursal comparado, Tomo I, Legis, Buenos Aires, 2009, pp. 6 y ss.

${ }^{44}$ Toda vez que ello, viene dado por la existencia de iliquidez por parte del deudor (parágrafos 17 y 18) que en términos generales resulta similar a una situación de cesación de pagos. 
la satisfacción colectiva de los acreedores por intermedio de la liquidación de los bienes del deudor y del producto de la distribución de dichos bienes, o bien, por medio del cumplimiento de un plan de insolvencia, especialmente ordenado a la continuidad de la empresa (pParágrafo 1). Ninguno de dichos objetivos es posible de ser alcanzado en un supuesto de quiebra sin bienes, que tal como se ha definido en este trabajo, refiere a la imposibilidad de soportar los costos del proceso.

Ahora bien, las facultades del Tribunal de la Insolvencia para rechazar una solicitud de apertura de quiebra, al inicio del procedimiento, también se extiende durante el curso del juicio, ya que de conformidad a la parágrafo 207, se suspenderá el proceso de insolvencia en caso de que los fondos obtenidos por el proceso de liquidación resultan insuficientes para solucionar los costes del procedimiento. En este caso y considerando que el procedimiento ya se ha iniciado, se deberá oír a los diferentes órganos involucrados (asamblea de acreedores, el administrador de la insolvencia y acreedores), todo de conformidad a la parágrafo 207.2. Por último, los bienes insuficientes se destinarán a cubrir aquellas expensas administrativas causadas en el proceso (parágrafo 207.3).

En todo caso, la declaración de inadmisibilidad de la solicitud de apertura de una quiebra cuando el deudor carezca de bienes para cubrir los costos del procedimiento, así como cuando se produzca la declaración de carencia de bienes, una vez iniciado el procedimiento, dará origen a un registro del deudor en un sistema público, el que eliminará el dato acerca de dicha declaración al cabo de cinco años.

\section{LEGISLACIÓN NACIONAL SOBRE LA QUIEBRA SIN BIENES}

En este capítulo estudiaremos la normativa nacional aplicable al problema de la quiebra sin bienes (a), lo compararemos con lo estudiado respecto de las legislaciones españolas y alemanas (b), concluyendo en un análisis de las deficiencias del sistema nacional, a la luz de lo estudiado en el derecho interno y comparado (c).

\section{Normativa nacional aplicable al problema}

La normativa nacional sobre el problema de la quiebra sin bienes, encuentra un reconocimiento no sistemático en la Ley de Quiebras (Capítulo IV del Código de Comercio), fundamentalmente, en los artículos 37 (sobre reducción de costes ${ }^{45}$ ), 97 (respecto de la incautación), 109 (respecto de la realización sumaria del

${ }^{45}$ El artículo 37 de la Ley de Quiebras, con la finalidad de reducir los costos del sistema, establece que en caso de quiebras sin bienes, el síndico sólo tendrá derecho a un honorario de quince unidades de fomento, las que serán soportadas por la Superintendencia de Quiebras, al igual que la notificación de la sentencia que declara la quiebra (la que se hará en extracto), y la notificación de la resolución que tenga 
activo), 158, 159, 160, 161 (todas dichas normas, respecto del sobreseimiento temporal), 165 (respecto del sobreseimiento definitivo), 235 a 240 (respecto de la rehabilitación) y artículo $2^{\circ}$ transitorio, todos del Capítulo IV del Código de Comercio (En adelante, indistintamente: Ley de Quiebras)

Dicho sistema se encuentra estructurado de manera confusa al no dar una solución unívoca al problema de la quiebra sin bienes (a.I). Además, la solución inicial al problema de la quiebra sin bienes, es el sobreseimiento temporal, lo que no evita los problemas de inhabilidades que genera la quiebra y deja subsistente el proceso, con posibilidades de reapertura en base a consideraciones no vinculadas necesariamente con la recuperación del crédito, relacionando además, indebidamente, el proceso de quiebras con la calificación concursal (a.II). Analizaremos, en dicho orden, los problemas detectados en la manera en que se enfrenta la situación de la quiebra sin bienes.

\subsection{Duplicidad de mecanismos legales para afrontar el problema de la quiebra sin bienes}

Nuestra legislación, de forma no sistemática, ha tratado de abordar una salida procesal a aquellas quiebras que plantean el problema de la inexistencia y/o insuficiencia del activo. Al respecto, se contemplan dos mecanismos, a saber:

Mecanismo 1: Sobreseimiento temporal por el hecho de que no aparezcan bienes al momento de la incautación (artículo 97 de la Ley de Quiebras).

a. De la labor de incautación efectuada por el síndico, que corresponde a la tarea inicial en el ejercicio de las funciones de dicho órgano (artículo 94 de la Ley de Quiebras), y que tiende a determinar la masa activa sobre la cual se pagarán los créditos verificados, puede resultar que no aparezca ningún bien perteneciente al fallido, de lo cual, debe dejarse constancia en un acta elaborada especialmente con dicho fin (artículo 97 de la Ley de Quiebras). Asimismo, de la diligencia de incautación se levantará un inventario, que en el supuesto estudiado, concluirá en la inexistencia de bienes objeto de incautación.

b. Dicho inventario se agrega a más tardar al día siguiente hábil a su facción, y se publicará por avisos, entendiéndose por dicha publicación, la notificación de su contenido. Desde dicho momento, comenzará a correr un plazo de quince días, tendientes a que el fallido o los acreedores efectúen las observaciones que correspondan a dicho inventario (artículo 98 de la Ley de Quiebras).

c. Si resulta que no se efectúan objeciones al contenido del inventario (en el sentido de la inexistencia de bienes), o bien ellas son rechazadas por el Tribunal de la Quiebra, deberá este órgano jurisdiccional pronunciar el sobreseimiento temporal de la quiebra,

por aprobada la cuenta definitiva, que sólo contendrá la mención de haberse aprobado dicha cuenta. Asimismo, las demás notificaciones que deban notificarse por aviso, se notificarán por el estado diario.

Dicha regulación, se incluyó recientemente en nuestra legislación de quiebras (por medio de las leyes № 20.004 y 20.073), si bien reducen los costos terciarios de la quiebra, no le ponen término, facilitando de esa manera, el verdadero problema de las quiebras sin bienes, que es precisamente su existencia. 
comunicando dicha decisión al fallido, acreedores y al síndico, comenzando a correr desde dicha notificación un plazo de treinta días para que este último órgano presente la cuenta definitiva de la quiebra.

Mecanismo 2: Realización sumaria del activo (artículo 109 de la Ley de Quiebras).

a. En la primera junta de acreedores (artículo 108 de la Ley de Quiebras) el síndico presentará su primera cuenta, en donde se contienen las diligencias realizadas hasta dicho momento, incluyendo las actuaciones de incautación (artículo 94 en relación con el artículo $108 \mathrm{~N}^{\circ} 1$ de la Ley de Quiebras).

b. Dicha junta de acreedores, debe realizarse en un plazo no inferior a treinta días ni superior a cuarenta días desde la fecha de la declaratoria de la quiebra, por lo que su realización, temporalmente, puede coincidir con los plazos de objeción del inventario presentados por el síndico, de acuerdo al mecanismo 1 antes indicado.

c. Pues bien, de la cuenta presentada por el síndico puede resultar que el producto probable de la realización del activo no supere las mil unidades de fomento, en tal caso, el síndico (hasta la fecha, provisorio) pasará a tener la calidad de definitivo, debiendo liquidar los bienes en un plazo no superior a seis meses (artículo 109 de la Ley de Quiebras), comenzando a correr, luego de dichos seis meses, un plazo de treinta días a los efectos de que presente la cuenta definitiva de la quiebra (artículo 30 de la Ley de Quiebras).

d. La apreciación sobre el producto probable de la realización del activo puede ser objetada por el fallido o los acreedores, generándose un incidente que deberá ser resuelto por el Tribunal de la Quiebra, quien puede oír, al respecto, la opinión de peritos (artículo 109 inciso $2^{\circ}$ de la Ley de Quiebras).

e. La declaración de la realización sumaria del activo dará origen al sobreseimiento temporal de la quiebra (artículo 158 NN $^{\circ}$ de la Ley de Quiebras), a solicitud exclusiva del síndico (artículo 159 de la Ley de Quiebras).

Analizados ambos mecanismos de solución al problema de la quiebra sin bienes surgen, indudablemente, distintos cuestionamientos a la forma en como se ha afrontado el problema por el legislador. En primer lugar, no se justifica una duplicidad de mecanismos para afrontar dicho asunto, toda vez que ello genera mayor nivel de conflicto y dudas interpretativas acerca de cómo actuarán los tribunales, dando señales poco claras a los agentes involucrados.

En segundo lugar, dicha duplicidad termina siendo más perjudicial, cuando pueden coexistir temporalmente ambas soluciones, produciéndose problemas innecesarios acerca de la preeminencia de uno u otro mecanismo. En efecto, la incautación opera inmediatamente efectuada la declaratoria de quiebra, por lo que el inventario y el acta de no haberse encontrado bienes pertenecientes al fallido serán puestos en conocimiento de los intervinientes en la quiebra, en un momento inicial de dicho procedimiento, comenzando a correr desde la publicación del aviso un plazo de quince días para las objeciones respectivas. Todo dicho íter de tramitación, será normalmente coetáneo a la realización de la primera junta de acreedores, en donde se presentará la primera cuenta del síndico, que, en lo sustancial, debe incluir el mismo inventario y acta de que trata el artículo 94 y 97 de la Ley de Quiebras, y que, eventualmente, puede resultar 
objetada, además de poder producirse una segunda objeción a la cuenta del síndico, lo que generará incidentes de cuestionamiento a una misma labor en el marco de dos cuestiones accesorias distintas, pero vinculadas con un mismo asunto, esto es, la inexistencia o insuficiencia de la masa activa del fallido.

En tercer lugar, dichas regulaciones son poco claras en sus presupuestos, porque tienden a atacar un mismo problema, pero en ámbitos conceptuales distintos. En efecto, el mecanismo 1, supone que el síndico no ha encontrado ningún bien perteneciente al fallido (o sea, caemos solamente en un supuesto de inexistencia de activo). En cambio, el mecanismo 2, supone que el síndico, en su primera cuenta, concluye que existe un producto probable de realización del activo inferior a mil unidades de fomento, lo que puede producir distintas interpretaciones, en el sentido de discutir si sólo comprende casos de inexistencia de activo o si también comprende supuestos de insuficiencia de activos, debido a que en el primer supuesto no es plausible ningún resultado probable de realización, al no existir activo que realizar; en segundo lugar, no solamente sería un mecanismo a disposición de quiebras sin bienes, sino que de aquellos procesos de quiebras en donde el activo sería suficiente para sustentar los costos asociados a su prosecución (en todo aquello que supere los costes del proceso y sea inferior a las mil unidades de fomento). Lo anterior significa que el mecanismo $\mathrm{N}^{\circ} 2$ no sería una solución adecuada al problema que se trata en este texto, ya que la manera de resolver el asunto del valor probable de realización del activo podría incluir informes de peritos tendientes a determinar la exactitud de la valorización del resultado probable de realización del activo, lo que aumentaría los costos frente a una situación de imposibilidad de pago, incluso de los gastos propios de la quiebra, de manera que dicho mecanismo no entregaría los elementos procesales adecuados para la solución del problema de la quiebra sin bienes, siendo demasiado caro para dichos efectos.

En cuarto lugar, no se justifica la limitación de la legitimación activa para solicitar el sobreseimiento temporal en el mecanismo $\mathrm{N}^{\circ} 2$ antes indicado, exclusivamente al síndico (artículo 160 de la Ley de Quiebras). Toda vez que el síndico tiene incentivos fuertes para mantener el proceso de quiebras, en una búsqueda de activos infructuosa, con la finalidad de obtener honorarios más elevados, ya que los mismos son establecidos sobre la base de los repartos de fondos provenientes de la realización del activo (artículo 34 de la Ley de Quiebras). Además, existe un contrasentido en permitir una legitimación activa amplia en el mecanismo $\mathrm{N}^{\circ} 1$ y no en el $\mathrm{N}^{\circ} 2$, ya que, desde una óptica de la magnitud de los efectos provocados por cada mecanismo, sería más justificable la limitación de legitimidad activa, en el primer supuesto mas no en el segundo, toda vez que resulta más fácil la constatación del hecho que el fallido posea bienes, que la constatación que el producto probable de realización del activo 
sea inferior a mil unidades de fomento, por lo que los espacios para el error judicial serían mayores en el primer mecanismo.

\subsection{El sobreseimiento temporal como solución inicial al problema de la quiebra sin bienes}

En cualquiera de los dos mecanismos señalados anteriormente, la solución legislativa resulta insuficiente a la finalidad de obtener una rápida conclusión del proceso de quiebra, en aquellos casos que no se justifica, manteniéndose las consecuencias perniciosas de la quiebra, no obstante la constatación de que no hay posibilidad de recuperación de los créditos verificados.

Lo anterior, debido a que, tanto en el mecanismo $\mathrm{N}^{\circ} 1$ como en el mecanismo $\mathrm{N}^{\circ} 2$ antes descritos, la solución lleva al sobreseimiento temporal, que de conformidad al artículo 161 de la Ley de Quiebras deja subsistente el estado de quiebra, y por tanto, las inhabilidades e incompatibilidades que supone dicho proceso de ejecución universal, así como los presupuestos en base a los cuales pueda calificarse una quiebra en sede penal. De hecho, el artículo 235 de la Ley de Quiebras, a propósito de la rehabilitación del fallido, dispone que solamente por dicho medio es posible cesar las inhabilidades que pesan sobre el fallido. Ahora bien, para que ello ocurra debemos esperar, en la mayoría de los casos, el sobreseimiento definitivo del fallido (artículo $165 \mathrm{~N}^{\circ} 2$ en relación con los artículos 236 y 238, todos de la Ley de Quiebras), sobre la base de una absolución en sede penal, generándose vinculaciones perniciosas entre ambos ámbitos, siendo precisamente ello lo que genera incentivos para que un acreedor abuse del procedimiento de quiebras, con la única finalidad de obtener venganza sobre el fallido.

De esta manera, la deficiencia detectada por Bonilla, Fischer, Tagle, Lüders y Mery, no resulta resuelta, ni siquiera con la Ley $\mathrm{N}^{\circ} 20.004$, por lo que su propuesta, en el sentido de centrar la legislación de quiebras, en aspectos vinculados solamente con la eficiencia en lo referente a la facilitación de la liquidación de activos, recuperación de deudas y reestructuración de empresas viables ${ }^{46}$, ha quedado olvidada en este punto, siendo necesario restablecer dicha idea por medio de una reforma legislativa.

Dicha deficiencia es replicada incluso en la normativa transitoria de la Ley de Quiebras, que en su artículo segundo dispone:

"Sin perjuicio de lo establecido en el artículo precedente, en todas aquellas quiebras que carezcan de bienes o en que éstos no alcancen a cubrir los gastos necesarios para su prosecución, el respectivo tribunal, de oficio o a petición de parte, dentro del plazo de sesenta días corridos desde la vigencia de esta ley, deberá decretar el sobreseimiento temporal. La resolución se notificará mediante la publicación de un aviso en el perió-

${ }^{46}$ Bonilla; Fischer; Lüders; Mery; Tagle, Análisis, cit. nota n. 11, p. 13. 
dico señalado para la publicación de la declaración de quiebra, si hubiere bienes; y en la forma prescrita en el artículo 50 del Código de Procedimiento Civil, si careciere de ellos".

Dicha norma, si bien constituye la única regla que dispone una regulación acerca de la quiebra sin bienes, como se ha conceptualizado en este texto, otorga una solución ineficiente, al dar como salida legal a dicha clase de procesos, precisamente, el sobreseimiento temporal.

Por último, el término de aquellos procesos de quiebras sin bienes, que no resultan justificados en la óptica de la eficiencia, pueden incluso demorar más y generar más pérdida de utilidad, al posibilitarse en el artículo 162 de la Ley de Quiebras que un acreedor solicite que se deje sin efecto un sobreseimiento temporal, en aquellos casos en donde se consignen dineros para los efectos de la prosecución del juicio. O sea, la misma normativa dispone que un sobreseimiento temporal puede perder valor si es que se ponen a disposición del tribunal dineros necesarios para solventar los gastos del proceso de quiebras, mas no, tendientes a ser efectiva la recuperación de deudas y pago de créditos. Dicha normativa resulta ser extraordinariamente perjudicial, porque posibilita un proceso de quiebras eterno, en la medida que exista alguien dispuesto a pagar por dicho fin, sin que la norma tienda a invertir en la búsqueda o recuperación de bienes. Lo anterior resulta en un absurdo mayor, cuando se piensa que de conformidad al artículo 160 de la Ley de Quiebras, la oposición al sobreseimiento puede provenir de justificar la existencia de bienes (lo que resulta plenamente aceptable); sin embargo, para dejar sin efecto un sobreseimiento temporal, ya no se requiere justificar la existencia de bienes, sino que simplemente subvencionar un proceso con miras a la venganza privada, y la estigmatización, lo que genera, por contrapartida, como hemos visto, mayores incentivos para conductas dolosas y oportunistas del deudor en el periodo previo a la quiebra.

\section{Comparación con sistema alemán y español}

De acuerdo a lo que se ha señalado anteriormente, tenemos que el sistema nacional sobre la quiebra sin bienes resulta completamente deficitario en comparación con las soluciones dadas por los sistemas comparados español, y alemán.

En efecto, en el sistema nacional la solución al problema de la quiebra sin bienes, cualquiera sea la vertiente de la que derive, se traduce en un sobreseimiento temporal, que no es sinónimo de conclusión del proceso de quiebras, en tanto, el estado de quiebra subsiste y sus efectos, también. Al respecto, la terminación del proceso de quiebras sin bienes, injustificado económicamente, subsistirá mientras no se efectúen previos y largos trámites en cuanto a obtener la conclusión del proceso de calificación penal (que puede durar todo lo 
que se extienda la prescripción de la acción respectiva), los sobreseimientos definitivos y la rehabilitación del fallido. Por su parte, tanto el sistema español como el alemán, al momento de resolver el problema de la quiebra sin bienes, traducen dicha declaración en una resolución con efectos concluyentes respecto de la suerte del procedimiento, en cuanto dicho proceso concluye irremediablemente.

Por su parte, si apreciamos los momentos en los cuales la legislación actúa, con la finalidad de poner término a una quiebra que no se justifica económicamente en razón de eficiencias, tenemos que nuestra legislación se coloca en un extremo y la alemana en el otro, siendo el punto medio la legislación española. Lo anterior, porque nuestra legislación no establece ninguna atribución al juez de la quiebra con la finalidad de impedir la declaratoria de quiebra en base a la inexistencia o insuficiencia del activo del fallido, lo que sí ocurre en la legislación alemana, sobre la base de proteger los intereses de los mismos acreedores, al impedir que sean arrastrados a un procedimiento que no será capaz de lograr la satisfacción, siquiera de los costos que implica. Entre estos modelos, el sistema español permite terminar un proceso por inexistencia de bienes y derechos del deudor, solamente durante el procedimiento de quiebra, una vez constituidos los órganos concursales y sobre la base de la constatación de la carencia de patrimonio del deudor.

Si consideramos la forma en cómo se regula el procedimiento de solución al problema de la quiebra sin bienes, nuevamente nuestra legislación resulta claramente ineficiente. Al respecto, existen diversos procedimientos, no siendo clara la regulación de los mismos y la manera de salvar las duplicidades o conflictos que pudieran originarse entre ellos. Dichos procedimientos, además, no serían adecuados para los fines de solucionar los problemas de las quiebras sin bienes, sino que estarían sobredimensionados para dichos efectos. Por último, la solución pasa por informes técnicos que incrementan los costos, cuando precisamente, se busca poner término al procedimiento, ya que éste no puede soportar dicha clase de gastos. Comparativamente, tanto el sistema español como el alemán resultan mejor formulados, ya que otorgan tramitación incidental al asunto, con plazos mayores, en el caso español, pero involucrando en la solución del problema solamente a los órganos de la quiebra, y en el caso alemán, con la obligación de disponer de los fondos existentes a la terminación del procedimiento.

En lo que se refiere a las vinculaciones entre la calificación penal y la solución al problema de la quiebra sin bienes, en el proceso de quiebra, debemos señalar que tanto la legislación chilena como la española conservan dicha vinculación, en cuanto impiden la conclusión del proceso si es que existen juicios de calificación vigentes, o bien, dichos procesos penales mantienen sus efectos. Lo anterior, resulta más grave en el caso nacional, ya que una vez eliminados 
los efectos criminales, es necesario de todas maneras iniciar un procedimiento de rehabilitación, que supone costos elevados de notificación y la tramitación de un proceso sumario ${ }^{47}$.

\section{Deficiencias de regulación nacional}

En el presente acápite se reiterarán las críticas y deficiencias observadas en el acápite (a) de este capítulo, desarrolladas en los puntos a.I y a.II anteriores, quedando por analizar otras deficiencias que es posible advertir de la legislación nacional y comparada.

Con todo, es necesario hacer presente que la deficiencia general de la forma en cómo la legislación nacional enfrenta el problema de la quiebra sin bienes, viene dada por no establecer las cargas procesales a los sujetos pertinentes y en los momentos apropiados, así como por no disponer de mecanismos jurídicos tendientes a prevenir la situación de insolvencia o de cesación de pagos.

Lo anterior resulta efectivo ya que, en primer lugar, como hemos visto, el presupuesto para la declaración de quiebra es la existencia de cesación de pago (artículo 43 de la Ley de Quiebras), sin necesidad de que el acreedor solicitante justifique la existencia de bienes de parte del futuro fallido, a fin de evitar quiebras en situaciones de inexistencia o insuficiencia del activo. Por su parte, cuando la quiebra es voluntaria, esto es, solicitada por el propio fallido, debe reunir una serie de requisitos, uno de los cuales es la relación de sus bienes (artículo $42 \mathrm{~N}^{\circ} 2$ de la Ley de Quiebras), lo que debería replicarse respecto de las quiebras necesarias.

Según lo que hemos visto, una de las formas tendientes a evitar que la quiebra sin bienes se transforme en un caso de abuso del procedimiento, es la de aumentar los costos de la reclamación, en este caso, de la solicitud de la declaratoria de quiebra. Una de las maneras de generar dicho incremento de los costos es por medio de la exigencia de señalamiento de los bienes que pertenecerían al deudor, con sus documentos justificativos. Lo anterior significaría generar una carga procesal y económica al acreedor, que aumentaría el ámbito del filtro legal de reclamaciones de procesos de quiebras, de forma que un número determinado de dichas peticiones que se formularían sin la mencionada exigencia no se plantearían, debido a que el valor esperado de su ganancia disminuiría al existir el aumento del costo judicial, sobre todo, si las

\footnotetext{
${ }^{47}$ Artículo 203 de la Ley de Quiebras: “La demanda de rehabilitación del fallido culpable o fraudulento se interpondrá ante el tribunal que haya conocido de la quiebra, y se sustanciará con el Superintendente. Podrán también apersonarse en el juicio de rehabilitación los acreedores cuyos créditos no hubieren sido enteramente pagados. La demanda de rehabilitación se notificará en igual forma que la declaratoria de quiebra y se sustanciará con arreglo a los trámites del juicio sumario. La sentencia que concede la rehabilitación será publicada en los diarios que designe el fallido".
} 
quiebras sin bienes no generan tasas de recuperación de dichos gastos. Dicha normativa, debe ir asociada con la condena en costas para el peticionario, en el caso de resultar falsos los datos entregados al efecto, e incluso podría pensarse en una sanción indemnizatoria similar a la contenida en el artículo 280 del Código de Procedimiento Civil, por los daños causados por la declaratoria de quiebra a un fallido cuya quiebra no ha sido justificada en razón de criterios de eficiencia. Ahora bien, la exigencia que se plantea no resulta completamente ajena a nuestra legislación, toda vez que los artículos 160 y 162 de la Ley de Quiebras disponen, con distintos matices, la subsistencia del juicio de quiebra sobre la base de probar la existencia de bienes pertenecientes al fallido. De esta manera, se pretende que dicha facultad procesal sea adelantada temporalmente, a fin de que sea ejercida cuando es posible evitar los costos que supone la quiebra, y no sólo cuando se trata de impedir su cierre temporal o de solicitar la reapertura de una quiebra sobreseída temporalmente. ${ }^{48}$

En segundo lugar, resulta central modificar la legislación de quiebras, con la finalidad de prevenir conductas oportunistas del deudor que lo lleven a acrecentar su situación de insolvencia o de cesación de pagos. De hecho, es en el periodo previo a la declaración de quiebras en donde la legislación debería actuar con mecanismos preventivos que intensifiquen la vigilancia y control del deudor. En tal sentido, la existencia de una regulación de medidas cautelares $^{49}$ anteriores a la declaración del concurso, como ocurre en la legislación española ${ }^{50}$, resulta plenamente justificable, con la finalidad de incentivar el

\footnotetext{
${ }^{48}$ Con todo, se debe tener en cuenta también el inciso tercero del artículo 45 de la Ley de Quiebras: "Si la solicitud fuere desechada en definitiva, el deudor podrá demandar indemnización de perjuicios al acreedor, si probare que éste ha procedido culpable o dolosamente".

${ }^{49}$ Ver por todos: Ariza Colmenarejo, María Jesús, "Medidas cautelares en el proceso de declaración y otras medidas del procedimiento concursal", en Olivencia, M.; Fernández-Nóvoa, C.; Jiménez de Pargas, R. (Dirs.), Tratado de Derecho mercantil. Derecho Procesal concursal, Vol. 7, Marcial Pons, Madrid, 2008, pp. 347 y ss.

${ }^{50}$ En efecto, el artículo 17 de la Ley 22/2003, establece que a petición del legitimado para instar el concurso necesario, el juez, al admitir a trámite la solicitud, podrá adoptar las medidas cautelares que considere necesarias para asegurar la integridad del patrimonio del deudor, de conformidad con lo previsto en la Ley de Enjuiciamiento Civil. Esto es, se posibilita la adopción de aquellas medidas tendientes a asegurar la integridad del patrimonio del deudor, de manera anticipada a que éste pudiera realizar diversos actos de disposición de dicho patrimonio, afectando las posibilidades de conformar un activo suficiente para salvaguardar los créditos en su contra. El objetivo de estas medidas es plenamente concordante con los fines del concurso, siendo la finalidad de las medidas prejudiciales exclusivamente la de mantener un status quo del activo del deudor que se sospecha se encuentra en insolvencia. Esta regulación, que queda entregada en su amplitud al juez de la quiebra, constituye una herramienta útil a efectos de evitar actos que después pueden ser de muy difícil revocación, debido a la intervención sucesiva de terceros adquirentes, que bien pueden evitar todo efecto de retroacción por medio de la buena fe, la que se presume. En consecuencia, su consagración permite, ex ante, dar respuesta a un problema que en la realidad es de muy difícil solución de forma ex post. Siendo importante resaltar el hecho de que el mismo artículo 17.2 de la Ley № 22/2003, permite resguardar los intereses del deudor,
} 
monitoreo privado de los acreedores y el control de la actuación de un deudor que se presume oportunista.

Al respecto, se ha propuesto una regulación de dichas cautelares con los siguientes elementos, a saber:

"Cualquier legitimado para instar a la declaración de la quiebra, o bien de oficio, el juez, al admitir a trámite la solicitud, podrá adoptar las medidas cautelares que considere necesarias para asegurar la integridad del patrimonio del deudor, de conformidad con lo previsto en el Código de Procedimiento Civil. El juez resolverá la solicitud de plano. El juez podrá pedir al solicitante que preste caución suficiente para responder de los eventuales daños y perjuicios que las medidas cautelares pudieran producir al deudor si la solicitud de declaración de concurso resultara finalmente desestimada. Declarada la quiebra, el juez del concurso se pronunciará sobre la permanencia de las medidas cautelares, en aquellos casos en donde la declaración no traiga consigo la inhabilidad del fallido, porque en dicho supuesto, las medidas prejudiciales deben cesar, al igual que cuando se desestime la declaración de la quiebra ${ }^{511}$.

Es importante hacer presente que el estudio elaborado por Bonilla, Fischer, Mery, Lüders y Tagle, identifica en los casos analizados ciertas conductas que deberían tender a ser prevenidas por medio de las medidas que se han señalado anteriormente. Dichas conductas son:

"- Los estados financieros -cuando existen- reflejan con anterioridad a la quiebra las dificultades financieras que el futuro fallido enfrenta;

- Hay una importante reducción del valor de los activos en el período que va desde que la empresa empieza a tener problemas hasta que quiebra. Además, hay una segunda pérdida -contable al menos- por la diferencia entre al valor contable de los activos y su valor de realización $n^{52 "}$.

Adicionalmente y con una finalidad de precaver las conductas de prevención respecto de comportamientos oportunistas del deudor, se necesita regular adecuadamente nuestras acciones de reintegro patrimonial, eliminando las incongruencias actuales, tales como que la fecha de cesación de pagos, de acuerdo al artículo 63 de la Ley de Quiebras, no puede ser fijada en un periodo superior a dos años con anterioridad a la declaratoria de quiebra, no obstante que la acción pauliana, solamente tiene un plazo de vigencia de un año (artículo 75 de la Ley de Quiebras y 2468 del Código Civil), por lo que su establecimiento resulta superfluo. En este mismo sentido, deberían regularse en la legislación

consagrando un sistema de responsabilidad objetiva por los perjuicios que a él se le ocasionen con la concesión de la medida, si es el caso que no se produce la apertura del concurso, lo que se satisface con un sistema de caución obligatoria que debe rendirse por parte del peticionario.

51 Carrasco Delgado, Nicolás, Las medidas precautorias desde la perspectiva del análisis económico del Derecho, Escuela de Graduados, Facultad de Derecho de la Universidad de Chile, Inédito, 2008, p. 34.

52 Bonilla; Fischer; Lüders; Mery; Tagle, Análisis, cit. nota n. 11, p 79. 
de quiebras, acciones de simulación de manera especial, con la finalidad de abordar un aspecto del Derecho Civil que se justifica en este ámbito, al constatar que habitualmente las distracciones de activos de los fallidos son realizados por medio de actos encubiertos en contratos simulados.

Partiendo de la premisa de que uno de los aspectos más trascendentes del concurso dice relación con la determinación del activo, es que deben consagrarse los incentivos necesarios para que dicha determinación sea efectuada lo más pronto y correctamente posible. En efecto, la rapidez y exactitud en dicha tarea servirá para determinar el estado de los negocios del deudor sobre la base de que una indeterminación en la suerte de los bienes del activo sólo produce ineficiencias. Es por ello que la legislación española ha regulado de manera expresa los deberes de colaboración del deudor con los órganos de la quiebra, estableciendo incentivos correctos en tal sentido, toda vez que si se produce una infracción a dichos deberes la consecuencia es un supuesto de presunción de dolo o culpa grave a efectos de la calificación culpable ${ }^{53}$, que puede producir como resultado una inhabilidad de hasta 15 años.

En este sentido, el artículo 42 de la Ley № 22/2003, señala: "1. El deudor tiene el deber de comparecer personalmente ante el juzgado de lo mercantil y ante la administración concursal cuantas veces sea requerido y el de colaborar e informar en todo lo necesario o conveniente para el interés del concurso. Cuando el deudor sea persona jurídica, estos deberes incumbirán a sus administradores o liquidadores y a quienes hayan desempeñado estos cargos dentro de los dos años anteriores a la declaración del concurso". "2. Los deberes a que se refiere el apartado anterior alcanzarán también a los apoderados del deudor y a quienes lo hayan sido dentro del período señalado".

Esta norma establece deberes generales y de una duración permanente en todo el procedimiento, impidiendo que el deudor pueda tener una posición estratégica respecto de la suerte del procedimiento, no pudiendo ocultar bienes, información, y debiendo, por contrapartida, comparecer e informar a los órganos del concurso cuantas veces sea necesario.

Corolario de dicha obligación es el artículo 45 de la Ley No 22/2003, que establece respecto de los libros de contabilidad y de la información del deudor lo siguiente: "El deudor pondrá a disposición de la administración concursal los libros de llevanza obligatoria y cualesquiera otros libros, documentos y registros relativos a los aspectos patrimoniales de su actividad profesional o empresarial".

En nuestra legislación, el supuesto de quiebra culpable vinculado con infracción a deberes de colaboración o información es mucho más restringido

${ }^{53}$ Cuando de acuerdo al artículo 165.2 se hubieran incumplido los deberes de información con el juez del concurso y con la administración concursal. 
que el establecido en la legislación española, porque importa la ausencia o no comparecencia al tiempo de la declaración o durante el curso de la quiebra, del deudor, y además, cuando se niegue éste a dar al síndico explicaciones sobre sus negocios. Por lo que se hace recomendable ampliar los supuestos en los términos generales que contempla la legislación española.

\section{CONClusiones}

Como hemos visto, la quiebra sin bienes la podemos definir como aquel procedimiento concursal de quiebras en donde el fallido no posee bienes (inexistencia de masa activa), o bien, poseyéndolos, son completamente insuficientes para satisfacer los costos asociados al proceso de quiebra (insuficiencia de masa activa).

La pregunta es: Frente a una quiebra en donde se den supuestos de inexistencia y/o insuficiencia de masa activa: ¿es conveniente (se justifica jurídicamente) la declaración y/o subsistencia de una quiebra?

Si consideramos que la generalidad de las legislaciones establece que el presupuesto fundamental para la existencia de la quiebra es la situación de insolvencia del deudor que se pretende fallido, deberíamos responder a la pregunta anterior, que ella no dice relación alguna con el problema fundamental de la quiebra, toda vez que ésta existirá, cuando se dé precisamente un supuesto de insolvencia o bien, en nuestra legislación, de cese en el pago de obligaciones. Lo referente a si aquel deudor que se pretende fallido, posee o no posee bienes, resulta impertinente para calificar, en sí mismo, el presupuesto de insolvencia. Podría tener importancia para explicar el porqué se llegó a una situación de insolvencia, pero en lo que aquí interesa responder, la inexistencia de bienes no podría ser un elemento de juicio a considerar para negar lugar a la apertura de un procedimiento de quiebras, cuando el deudor efectivamente se encuentra en estado de no poder cumplir con sus obligaciones.

Lo anterior resulta plenamente justificable, desde la lógica expuesta, si consideramos que la insolvencia constituye un estado al que se llega, normalmente, luego de que el deudor ha actuado en perjuicio de sus acreedores, simulando créditos y ocultando o distrayendo bienes. De esa forma, pretender agregar un requisito adicional a la apertura de la quiebra, en lo referente a la prueba de existencia y suficiencia de bienes, significaría incentivar al deudor a aquellas conductas que generen, precisamente, el efecto de disminuir su activo, llevándolo a la inexistencia o insuficiencia de la que se ha hablado.

Conjuntamente con dicho argumento, la quiebra dará paso a oportunidades procesales para obtener el reintegro de activos disimulados o bien, distraídos por el deudor, pasando de una inexistencia e insuficiencia de activos, a un estado en donde la masa activa de la quiebra se encuentre en condiciones de satisfacer los créditos verificados. 
Considerando dichos argumentos, la respuesta a la pregunta antes planteada sería: Es plenamente conveniente la declaración y/o subsistencia de una quiebra aun cuando nos encontremos en situación de inexistencia o insuficiencia de bienes. Sin embargo, en el presente texto, se sugiere que en ambos casos la respuesta debería ser: No es conveniente que exista un juicio de quiebras.

En primer lugar, quizás habría que reformular la pregunta, en los siguientes términos: Frente a una quiebra en donde se den supuestos de inexistencia y/o insuficiencia de masa activa: ¿constituye la mejor opción (se justifica económicamente) la declaración y/o subsistencia de una quiebra?

Frente a dicha pregunta, los sólidos argumentos antes expuestos empiezan a declinar su fuerza relativa. Toda vez que toda decisión procesal importa costos. Así, la opción por un juicio de quiebra, en casos de inexistencia o insuficiencia de activos, lleva aparejado un costo de oportunidad, esto es, un escenario alternativo, que es: La no declaración de la quiebra, o bien, su no subsistencia. Si entendemos que la normativa de quiebras involucra un objetivo de eficiencia en la asignación de los recursos, tenemos que analizar qué escenario resulta más costoso, a efectos de poder optar por el otro escenario. Ya que nadie querría razonablemente, sacrificar recursos y costos sin una finalidad de cierta rentabilidad. Y si existiera ese nadie, el Derecho no tiene por qué resguardar sus intereses, en la medida que nos llevan a un derroche de recursos. El Derecho Procesal, y la quiebra, se traduce en un procedimiento, debe tender necesariamente a la reducción de los costos innecesarios, más aún cuando no se justifican por sus consecuencias, y más aún en la quiebra, en donde razones de eficiencia se encuentran sino explícitas, de todas maneras implícitas en su regulación.

Sobre la base anterior, es necesario explicar las razones que nos llevan a la conclusión de que frente a una quiebra sin bienes, es mejor la no declaración ni subsistencia de la quiebra.

En primer lugar, la quiebra, como procedimiento concursal especial, importa y supone grandes costos. De partida, si pensamos en una quiebra necesaria (aquella solicitada por un acreedor), se exige una consignación previa, la que se fundamenta en la existencia de costos implícitos para el debido funcionamiento de los órganos de la quiebra. En segundo lugar, desde un punto de vista orgánico, existe una serie de intervinientes u órganos en el proceso concursal, dentro de los que encontramos al síndico y la junta de acreedores. Adicionalmente, existe una serie de gastos propios que lleva aparejado la quiebra, como lo son, la existencia de publicaciones, diligencias de incautación, oficios, allanamientos, etc. El funcionamiento mismo de la quiebra resulta lento y pesado, en el sentido de que muchas decisiones deben adoptarse por organismos colegiados, cuya posibilidad de frustración de objetivos es alta, en razón de la exigencia legal de quórum de constitución y de aprobación de acuerdos. En este sentido, el 
Banco Mundial ha señalado como una de las deficiencias del sistema nacional de derechos de los acreedores e insolvencia, lo largo y costoso de los procedimientos judiciales tendientes a la satisfacción de créditos, dentro de los cuales, la quiebra alcanza un sitial destacado.

En consecuencia, el costo de la decisión de optar por un proceso de quiebra, considerando el escenario descrito, resulta altísimo. Con mayor razón, si estamos en presencia de una situación de inexistencia o insuficiencia de bienes, que como se sabe, formarán la masa activa sobre la cual los acreedores se pagarán de sus créditos.

Ahora bien y en segundo lugar, si el argumento para mantener la respuesta a favor de la declaración o subsistencia de la quiebra, es la posibilidad de llevar a cabo acciones de reintegro del patrimonio distraído del fallido, tenemos que la solución tampoco resulta del todo satisfactoria. En efecto, dichas acciones en nuestra legislación contienen fallas regulatorias evidentes, en los siguientes aspectos: (a) Plazos para su ejercicio; (b) Procedimiento al que se sujetan dichas acciones; (c) Inexistencia de regulación de medidas prejudiciales especiales y adaptadas a la quiebra, y (d) Inexistencia de regulación clara acerca de los deberes del deudor, al no existir sanción pertinente a la no colaboración del fallido.

Lo que se quiere decir es que, normalmente, aquellas quiebras que a la fecha de su declaración son de aquellas que hemos denominado sin bienes, mayormente subsistirán en dicho carácter durante el proceso de quiebras.

A todo lo anterior debemos agregar un antecedente adicional, referente a las inhabilidades que trae aparejadas la quiebra. Ellas imposibilitan y extraen un agente económico del sistema, negando la posibilidad cierta que pudiera volver a actuar en el mundo de los negocios y, con ello, imposibilitando más aún que los créditos pudieran llegar a satisfacerse algún día.

En razón de lo dicho, se hace necesario extraer consideraciones propias del Análisis Económico del Derecho, y de las legislaciones de Alemania y España, que pudieran posibilitar una reforma al sistema concursal chileno en lo referente al asunto de las quiebras sin bienes, sobre la base de los siguientes conceptos:

a. Que el acreedor asuma el costo de la prueba de la existencia y suficiencia de bienes;

b. Que el sistema imponga deberes de información al deudor respecto de la existencia y suficiencia de bienes;

c. Que el juez de la quiebra tenga facultades para excluir un procedimiento de quiebras, cuando no se justifique, en razón de la existencia y suficiencia de bienes;

d. Que se contemple como causal de conclusión de la quiebra, en cualquier momento, la inexistencia o insuficiencia de bienes; 
e. Que se elimine la regulación existente acerca de los sobreseimientos y la rehabilitación, uniformando dicha normativa en causales específicas de conclusión de la quiebra;

f. Que se regule adecuadamente, en sus aspectos sustanciales y procesales, las acciones de reintegro de bienes distraídos por el deudor;

g. Que se delimiten los ámbitos de responsabilidad penal concursal, sobre la base de la independencia respecto de la acción civil que lleva a la declaración de la quiebra, y

h. Que se posibilite la rehabilitación del fallido, con la finalidad de reintegrarse al mundo de los negocios y satisfacer los créditos de sus acreedores, salvo supuestos de un dolo concursal especial.

Para el logro de dichos objetivos debemos redefinir el presupuesto de la insolvencia, limitándolo como presupuesto objetivo para la declaración de quiebra, cuando existiendo imposibilidad de pago de los créditos, el proceso de quiebra resulta justificado para los fines de la satisfacción de los acreedores, considerando como aspecto relevante la posibilidad de continuación de la empresa desde una perspectiva eficiente.

\section{BiBLIOGRAFÍA}

Ariza Colmenarejo, María Jesús, "Medidas cautelares en el proceso de declaración y otras medidas del procedimiento concursal", en OlivenCIA, M.; FernándeZNovoa, C.; Jiménez de Pargas, R. (Dirs.), Tratado de Derecho mercantil. Derecho Procesal concursal, Vol. 7, Marcial Pons, Madrid, 2008.

Banco Mundial, Informe sobre Observancia de Estándares y Códigos (Chile), Junio 2004. En: http://www-wds.worldbank.org/external/default/main?men uPK=64187510\&pagePK $=64193027 \&$ piPK $=64187937 \&$ theSitePK $=52367$ $9 \&$ menuPK $=64154159 \&$ searchMenuPK $=64258544 \&$ theSitePK $=523679 \&$ entityID=000160016_20060126181835\&searchMenuPK=64258544\&the SitePK=523679 [visitado el 14/06/2010].

Beluddo, Rafael, "Causas de conclusión del concurso", en Rojo, Ángel; Betrán, Emilio (Dirs.), Comentario a la ley Concursal, Tomo II, Civitas, Madrid, 2004.

Bonilla, Claudio; FisCher, Ronald; LüDers, Rolf; Merr, Rafael; TAGle, José, Análisis y Recomendaciones para una reforma de la ley de quiebras, Documentos de Trabajo del Centro de Economía Aplicada del Departamento de Ingeniería Industrial de la Universidad de Chile, 2004, № 191.

Carrasco Delgado, Nicolás, Las medidas precautorias desde la perspectiva del Análisis Económico del Derecho, Escuela de Graduados, Facultad de Derecho de la Universidad de Chile, Trabajo Inédito, 2008.

Catalano, Elena María, L'abuso del processo, Giuffrè Editore, Milano, 2004. 
Coleman, Jules, "The Grounds of Welfare", The Yale Law Journal Vol. 112, 2003.

Cooter, Robert; Ulen, Thomas, Derecho y Economía, Fondo de Cultura Económica, Ciudad de México, 1998.

Cossıo Díaz, José Ramón, Derecho y análisis económico, Fondo de Cultura Económica, Ciudad de México, México, 1997.

Dasso, Ariel A., Derecho concursal comparado, Tomo I, Legis, Buenos Aires, 2009.

Goudeau Gómez, Bayardo, "Concepto sobre la insolvencia, cesación de pagos, suspensión de pagos, crisis económica y empresas en dificultad", en Román Rodríguez, Juan Pablo (Coord.), Salvamento de las empresas en crisis, Editorial Jurídica de Chile, Santiago, 2001.

Habermas, Jürgen, Faktizität und Geltung, Suhrkamp, Frankfurt, 1992.

Marinon, Luiz Gilherme; Pérez Ragone, Álvaro; Núñez OJeda, Raúl, Fundamentos del proceso civil. Hacia una teoría de la adjudicación, Abeledo Perrot, Santiago, 2010.

Pacheco Vergara, Andrés, La Administración Concursal, Editorial Aranzadi, Pamplona, 2009.

Posner, Richard, El análisis económico del Derecho, Fondo de Cultura Económica, Ciudad de México, 1992.

Puga VIAL, Juan Esteban, Derecho Concursal. El juicio de Quiebras, Tomo I, Editorial Jurídica de Chile, Santiago, 1999.

Sandoval López, Ricardo, Derecho comercial. La insolvencia de la empresa, Tomo IV, Editorial Jurídica de Chile, Santiago, 2007.

Shafer, Hans-Bernd; Ott, Claus, Manual de Análisis Económico del Derecho Civil, Tecnos, Madrid, 1991.

ShavelL, Steven, Fundations of Economic Analysis of Law, Belknap Press of Harvard University Press, Cambridge, 2004.

SPECTOR, Horacio, "Justicia y Bienestar desde una perspectiva de derecho comparado", en Kluger, Viviana (Comp.), Análisis Económico del Derecho, Heliasta, Buenos Aires, 2006.

TIRADO, Ignacio, Los administradores concursales, Civitas, Madrid, 2005.

Veljanovski, Cento, Economía del Derecho. Un texto Introductorio, Ediciones Universidad Diego Portales. Santiago, 1990. 
